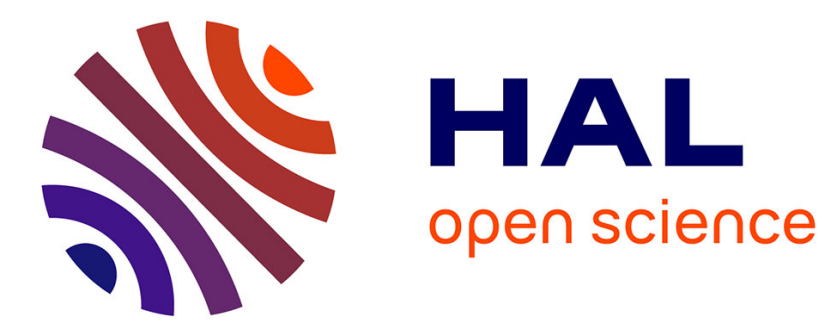

\title{
Intermittent renewable generation and network congestion: an empirical analysis of Italian Power Market
}

Faddy Ardian, Silvia Concettini, Anna Creti

\section{- To cite this version:}

Faddy Ardian, Silvia Concettini, Anna Creti. Intermittent renewable generation and network congestion: an empirical analysis of Italian Power Market. 2015. hal-01218543

HAL Id: hal-01218543

https://hal-polytechnique.archives-ouvertes.fr/hal-01218543

Preprint submitted on 21 Oct 2015

HAL is a multi-disciplinary open access archive for the deposit and dissemination of scientific research documents, whether they are published or not. The documents may come from teaching and research institutions in France or abroad, or from public or private research centers.
L'archive ouverte pluridisciplinaire HAL, est destinée au dépôt et à la diffusion de documents scientifiques de niveau recherche, publiés ou non, émanant des établissements d'enseignement et de recherche français ou étrangers, des laboratoires publics ou privés. 


\title{
Intermittent renewable generation and network congestion: an empirical analysis of Italian Power Market
}

\author{
Faddy Ardian ${ }^{1}$ \\ École Polytechnique \\ Silvia Concettini ${ }^{2}$ \\ École Polytechnique \\ Anna Creti \\ Université Paris Dauphine and École Polytechnique
}

\footnotetext{
${ }^{1}$ faddy.ardian@polytechnique.edu

2 silvia.concettini@polytechnique.edu
} 


\section{Introduction and literature review}

The interest in alternative energy has sparked in Europe as the climate change problem emerged. The 2009 Climate and Energy package has motivated European governments to stimulate renewable energy penetration through supporting schemes in order to meet the target of a $20 \%$ share of EU energy consumption produced from renewable sources by 2020. According to the more recent figures from Eurostat, the share of renewables in gross final energy consumption has reached $14.95 \%$ in the EU28 in 2013. The economic literature has emphasized the likely reductions of wholesale prices entailed by increasing renewable supply and originated from the displacement of higher variable cost production in the merit order ranking. This phenomenon is referred to as "merit order effect". A larger renewable production has also determined an increase in wholesale price variance as a consequence of technological dependency on exogenous variables. Evidences of these effects have been empirically analyzed for instance in Australia (Cutler et al., 2011), Austria (Wurzburg at al., 2013), Denmark (Jónsson et al., 2010), Germany (Wurzburg at al., 2013; Ketterer, 2014), Israel (Milstein and Tishler, 2011), Ireland (O’Mahoney and Denny, 2011), Italy (Clo et al., 2015), Spain (Gelabert et al., 2011).

Besides the effects on prices, renewable supply has raised some concerns regarding network functioning and congestion management. Some geographical locations seem particularly well suited for the installation of new capacity due to the abundance of natural resources (e.g. the North for wind and the South for solar in both Germany and Spain). Nevertheless, the existing networks may not be adequately developed to guarantee a constant and smooth flowing of more efficient RES production ${ }^{3}$ toward consumption sites. When production and consumption sites do not coincide and are, on the contrary, very far from each other, increasing renewable output may put an additional stress on the infrastructure, amplifying transportation needs and multiplying congestion occurrence. The opposite happens if renewable supply relieves deficits of production in historical importing regions. Hence, depending on the location of supply and demand, a larger renewable production may have a positive or negative effect on congestion occurrence and, as a consequence, on congestion cost.

The impact of renewable on network congestion may be explicitly investigated in national electricity markets organized as two or more inter-connected sub-markets (or bidding zones) where transmission rights are assigned through implicit auctions. ${ }^{4} \mathrm{~A}$ sub-market or bidding zone is defined as the largest geographical area within which market participants can offer and buy energy in the intra-day, day-ahead and longer time frame markets; its boundaries are generally settled based on physical transmission limits in order to achieve an efficient use of the infrastructure. In the absence of transmission constraints, prices are equal across zones; when inter-zonal constraints are binding, zonal market prices diverge. With an implicit auctioning for transmission rights, transmission capacity is (implicitly) included in the auctions of electricity. In other words, the resulting electricity prices per area reflect both the cost of energy in each internal bidding area and the cost of congestion. Implicit auctions ensure that power flows from the surplus areas (low price areas) towards the deficit areas (high price areas). The analysis of the links between renewables and congestion results to be extremely relevant in the path toward the implementation of the European Electricity Target Model which envisages the creation of bidding zones (defined or not by national borders) within a single EU market. Because of heterogeneous generation mix, geographical conditions, RES support schemes and national network configura-

\footnotetext{
${ }^{3}$ In terms of marginal cost.

${ }^{4}$ The same analysis can be applied to market coupling.
} 
tions across EU Members, the European Target Model may face at a larger scale the same challenges of those Countries with bidding areas having experienced a significant renewable penetration.

This article aims at contributing to the scant literature on the effect of increasing renewable power production on congestion frequency and cost. Schröeder et al. (2013) have provided a technical and economic analysis of congestion as a consequence of integration of renewables in Germany, concluding that actual transmission development plans are insufficient to cope with increasing penetration and the installation of a new transmission facility seems to be welfare-improving. Woo et al. (2011) study the effect of increasing wind generation on zonal price differences in Texas ERCOT power market with an ordered logit model for the occurrence of congestion and an OLS model for the level of paired-price differences. The analysis stems from the observation that wind generation is mostly concentrated in the West zone, which is scarcely populated, whereas generation capacity in Houston zone falls short of its zonal load. The authors show that rising wind supply, nuclear generation, load from non-West zones and gas price increases the likelihood and the size of strictly positive paired-price differences between the West and the other zones; ${ }^{5}$ increasing the load in the West zone has exactly the opposite effect since it reduces exporting needs.

In order to assess the impact of increasing renewable output on congestion frequency and cost, we use Italian electricity market as a case study. For its particular features, Italy serves well our research purpose. Firstly, the Italian Power Exchange is composed of six regional sub-markets, which aggregate in macro-zones all administrative regions. Since each of the zones has its own specific generation mix, they provide heterogeneity in our samples. Secondly, the ambitious support policies for the development of renewable power sources have generated a significant amount of new investments in solar and wind power plants. According to the latest available data, ${ }^{6}$ the supply from these power plants has covered $15.89 \%$ of the electricity purchased in the day-ahead market in 2014. Solar and wind production sold through the day-ahead market have registered an increase of $267.2 \%$ from 2010 to 2014. Southern regions have shown the highest growth rate due to the favorable weather conditions. This rapid growth is an essential characteristic for studying RES impact on congestion. Thirdly, the inter-zonal transmission capacities are not equally distributed in the Italian electricity system. In particular, transmission lines that connect the islands to the Italian peninsula have limited capabilities. With high renewable penetration in some regions and transmission limitations, Italy has the ideal conditions for a case study.

To empirically test the effect of renewables on congestion in Italy, we have built a unique database collecting and matching data with hourly frequency for a five year period (2010-2014) from two sources: GME, the market operator, which publishes the hourly offers in the day-ahead market together with equilibrium prices, quantities and inter-zonal transits; REF-E, a consulting group, who has created a list of Italian power plants classified by technology and geographical location. We have estimated then two econometric models performed on five zonal pairings: a multinomial logit model, whose dependent variable has three discrete values capturing both the occurrence of congestion and its direction, and a 3 stage least square model which seeks to quantify the effects of renewable production on implicit and explicit congestion costs. ${ }^{7} \mathrm{Up}$ to our knowledge, Sapio (2014) is the only author testing the effect of larger solar

\footnotetext{
${ }^{5} \mathrm{~A}$ strictly positive paired-price difference occurs when the West price is lower than the price in the other zones and vice-versa, meaning that the congestion is "coming from the West".

${ }^{6} \mathrm{GME}$, Annual Report 2014.

${ }^{7}$ The difference between these two type of congestion costs will be described in the following sections.
} 
and wind generation on congestion between Sicily and Southern Italy using a binary dynamic logit model and a vector autoregressive model on 2012 hourly data. The likelihood of congestion tout-court seems to increase with the demand in Sicily and the supply of solar in the rest of Italy and to decrease with all other regressors (demand in the rest of Italy, solar and wind supplies in Sicily, wind supply in the rest of Italy). When directional congestion is analyzed the author finds that a rise in the demand in Sicily and in the supply of solar in the rest of Italy decreases the likelihood of congestion from Sicily, while a rise in the load in the rest of the peninsula, in the supply of wind and solar in Sicily and in the indicators on market power have the opposite effect; the opposite pattern is found for congestion to Sicily. With the VAR model the author validates logit results.

This article originally contributes to the literature in several ways. First, we enlarge the scope of the analysis by considering all Italian neighbouring zones in order to verify the consistency of the empirical models beyond the specificities of each pair. Second, we employ a multinomial logit model, instead of a binary model, in order to separately capture the effect of increasing renewable production on the probability of both directional congestions (to and from) compared to the benchmark situation of no congestion. Third, we consider zonal figures on production and demand instead of aggregated figures to isolate the contribution of each zone to the occurrence of congestion. Fourth, we estimate the impact of renewable output not only on congestion frequency but also on congestion cost, something that has never be done before in the literature. Fifth, the 3 stage least square model allows us to solve endogeneity issues concerning hydroelectric production and to consider the national electricity system as a whole with correlated equations.

Our analysis suggests that the effect of a larger local wind and solar supply is to decrease the probability of suffering congestion in entry and to increase the probability of causing a congestion in exit compared to no congestion case. Increasing hydroelectric production has a similar effect. A rise in local demand on the contrary increases the probability of congestion in entry (due to larger import) and decreases the probability of congestion in exit. These results hold for both importing and exporting regions, but importing regions are much less likely to cause congestion in exit, therefore the installation of new RES capacity in these zones may have a positive effects in terms of flow balance between regions. The estimations on congestion cost reveal that, due to the merit order effect, local larger renewable tend to push the congestion cost towards negative value as it decrease the marginal cost for balancing the system. Much bigger shock of renewable quantity consequently could reduce saturated line and merge the zone (congestion cost $=0$ ) or could change the direction of the flow into the opposite direction (congestion cost $<0$ ) because of excessive supply. This is true for all the zone in the case of explicit congestion cost, but it is only applied in importing regions when we look at the implicit congestion cost. ${ }^{8}$ Therefore, increase of renewable should be promoted in the importing zones, but the overall growth should be controlled in order to avoid congestion to the opposite direction.

The remainder of the paper is organized as follows. Next section briefly describes Italian electricity market and the rules for congestion management. The third section provides an overview of the day-ahead market transactions in terms of generation mix, interzonal transits and price differences between neighboring zones. The forth section is dedicated to the econometric analysis. The last section concludes.

\footnotetext{
${ }^{8}$ We will explain the difference between explicit and implicit congestion cost in the section 4 .
} 


\section{Italian electricity market}

The Italian Power Exchange (IPEX) is composed by a spot market (MPE), a forward market (MTE) and a platform for the physical delivery of contracts concluded on the financial derivatives segment of the Italian Stock Exchange (CDE). The spot market is composed by three sub-markets: the day-ahead (MGP), the intra-day and the ancillary services markets. GME (Gestore dei Mercati Elettrici) manages the IPEX together with the OTC Registration Platform for forward electricity contracts that have been concluded off the bidding system. Our analysis focuses solely on the MGP (Mercato del Giorno Prima), the day-ahead market. The Italian geographical market consist of 7 foreign virtual zones, 6 geographical zones and 5 poles of limited production (national virtual zones). A stylized representation of the geographical market with the most relevant links between zones is reported in Figure 1 . The 20 administrative regions composing the Italian territory are aggregated in the 6 geographical zones (Fig. 2). The poles of limited production are coupled with the closest geographical zone: Monfalcone (MFTV) is associated to NORD, Brindisi (BRNN), Foggia (FOGN) and Rossano (ROSN) to SUD and Priolo (PRGP) to SICI.

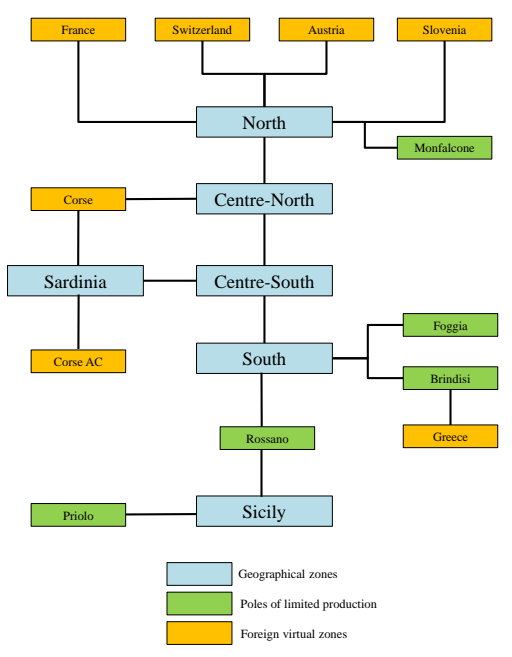

Figure 1: A stylized representation

In this market, transactions take place between the ninth day before the day of physical delivery and the day before the day of delivery. The sellers submit hourly offers for each generating unit specifying the quantity and the minimum price at which they are willing to trade their power. The aggregated supply curve is built according to the merit order in an ascending order of price. In a symmetrical way, the market demand curve is generated through the aggregation of single bids in a descending order of price. ${ }^{9}$ The hourly market price is determined by the intersection of the

\footnotetext{
${ }^{9}$ For each day and each offer/bid point, a maximum of 24 bids/offers may be submitted. Three types of offer/bid exist: simple, consisting of a pair of values indicating the volume of electricity offered/bid in the market by a market participant and the price for a given hour; multiple, consisting of the division of an overall volume offered/bid in the market by the identicle market participant for the same hour; pre-defined, consisting of simple or multiple offers/bids, which are daily submitted to GME (GME).
} 

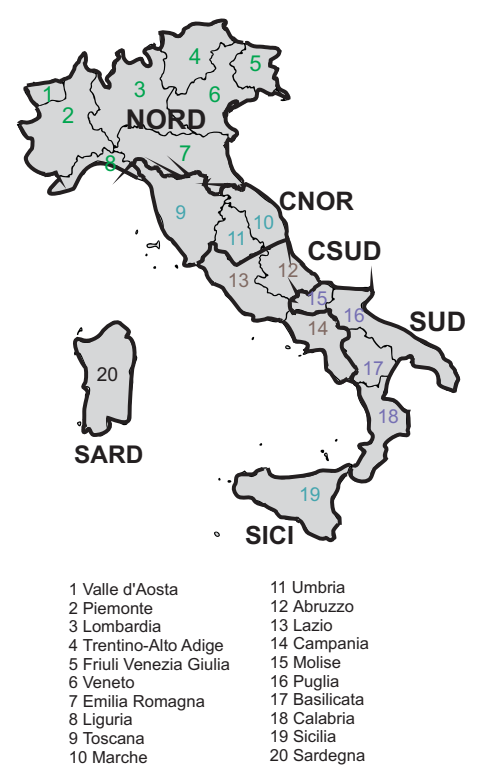
Figure 2: Italian geographical zones

demand, and the supply curves, following an iterative procedure. Firstly, the geographical market is considered as unique: if the day-ahead production/consumption plan respects all network constraints across zones (no congestion), a single price for the whole country emerges. ${ }^{10}$ On the contrary, if a network constraint is saturated, then the geographical market is divided into two sub-markets, each one aggregating all the zones above and below the saturated constraint. The market demand and supply curves are rebuilt for the two sub-markets (taking into account the quantity that can flows between zones up to the transmission limit), and two zonal prices result. The hourly auction is a uniform price auction which means that all accepted units are entitled to receive the system marginal price (or prices when de-zoning arises because of transmission congestion). Figures 3 and 4 illustrate through an example how the inter zonal price mechanisms work under uniform auction rule without and with congestion respectively.

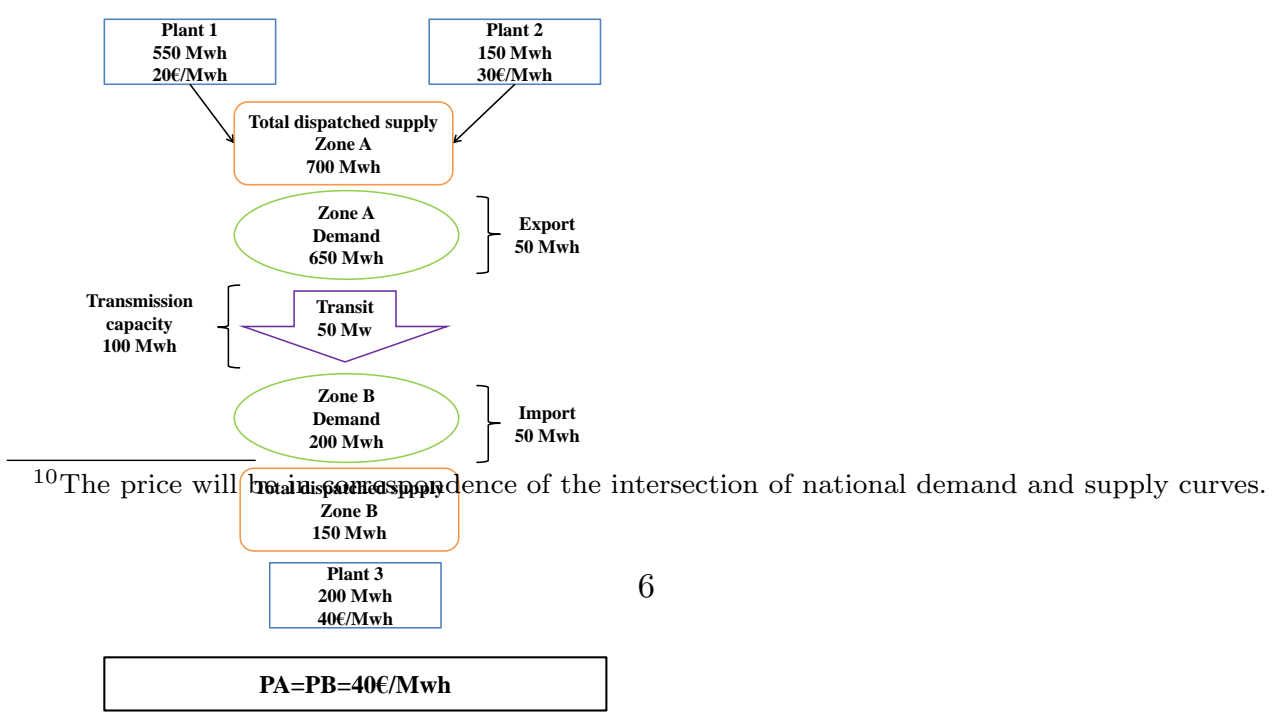

Figure 3: Pricing without dezoning 


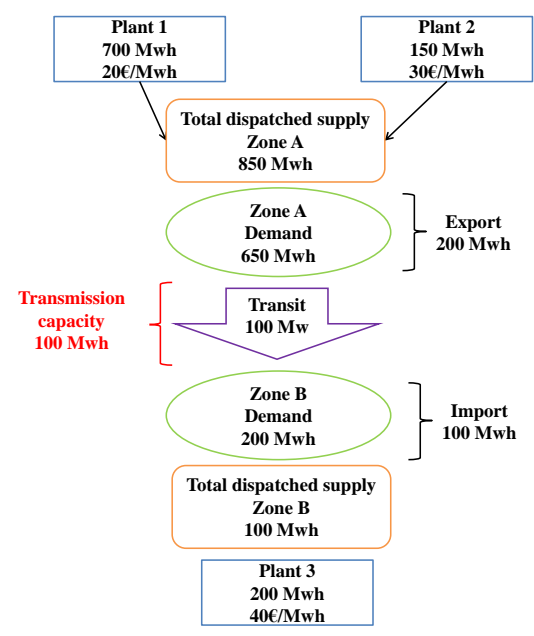

$\mathrm{PA}=30 € / \mathrm{Mwh}<\mathrm{PB}=40 € / \mathrm{Mwh}$

Figure 4: Pricing with dezoning

In the permanence of network saturation, the process of sub-setting the market continues until all constraints are satisfied (Fig. 5).
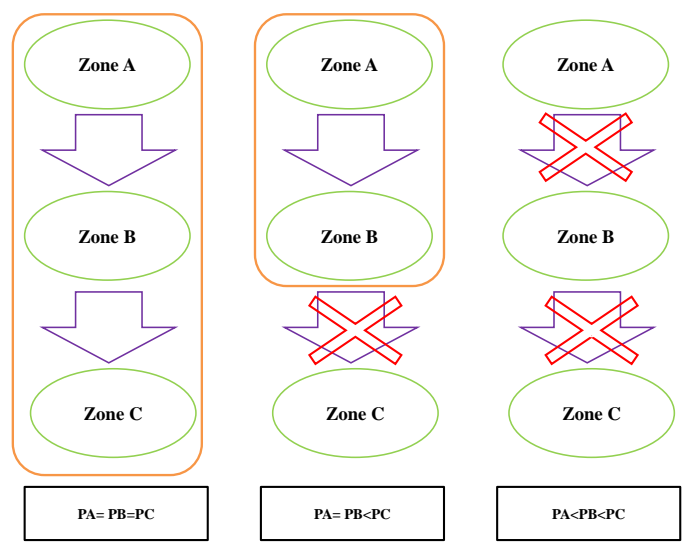

Figure 5: Multiple congestion

While producers receive the zonal prices in the occurrence of congestion, the buyers pay the National Single Price (PUN) for the electricity bought in the pool: the PUN is an average of zonal prices weighted for the zonal purchases. ${ }^{11}$

To better gauge the relevance of congestion phenomenon in Italy, we have reported in Table 1 its frequency and the average number of zonal divisions for the five year

${ }^{11}$ The purchased quantity should be netted of purchases from pumped-storage units and from foreign zones. In the example reported in Fig. 4 the PUN would be equal to $32.35 € / M w h$ :

$$
\mathrm{PUN}=\frac{\sum P_{i} Q_{i}}{\sum Q_{i}}=\frac{(30 \times 650)+(40 \times 200)}{650+200}=32.35
$$


period 2010-2014. We observe that congestion frequency has never gone below $82 \%$, reaching a peak in 2013 with the network congested $93.6 \%$ of the time. The average number of sub-markets has slowly decreased from 2.416 to 2.28 between 2010 to 2012 to rise again in in 2013 and 2014.

\begin{tabular}{cccccc}
\hline & Frequency & Percentage & Zonal divisions (Mean) & Std & $\mathrm{N}$ \\
\hline 2010 & 7210 & $82.3 \%$ & 2.416 & 0.809 & 8760 \\
2011 & 7403 & $84.5 \%$ & 2.307 & 0.686 & 8760 \\
2012 & 7921 & $90.1 \%$ & 2.240 & 0.531 & 8784 \\
2013 & 8205 & $93.6 \%$ & 2.278 & 0.518 & 8760 \\
2014 & 8044 & $91.8 \%$ & 2.284 & 0.543 & 8760 \\
\hline
\end{tabular}
Table 1: Congestion frequency

\section{Day-ahead market: generation mix, transits and zonal price differences}

This section is devoted to the description of Italian production mix, interzonal transits and zonal price differences as they result from the day-ahead ex-post market data. From 2010 to 2014, the contribution of Italy's main source of electricity, gas, has gradually decreased with the 2014 quantity (75.1 Twh) representing almost the half of 2010 figure. RES supply has surpassed total CCGT production for the first time in 2014 (100.9 Twh versus 75.1 Twh). In this year, renewable production has exceeded the target established in the National Renewable Action Plan (NREAP) to produce $100 \mathrm{TWh}$ of renewable energy by 2020. Even with high renewable penetration, Italy is still a net importer. The statistics suggests that on average $15.9 \%$ of the quantity accepted in the day-ahead market is supplied by neighboring countries. ${ }^{12}$ A detailed figure of the quantity sold in the day-ahead market by production source for the period 2010-2014 is reported in the Appendix (Figure 9). The breakdown of renewable supply by technology (Figure 6) reveals that wind and solar have experienced the strongest growth. Solar production registers the highest increase as the supply of 2014 is 4.5 times the one of 2010. As a result, in 2014 the solar accounts for $29.9 \%$ of total renewable supply and $10.7 \%$ of the total production mix. Wind supply in 2014 is 2.6 time the production in 2010 reaching $14.6 \%$ of total renewable supply. Hydro production has decreased instead from 2010 to 2012 to rise again afterwards. In 2014, it represents half of total renewable production.

Physical exchanges resulting from the day-ahead auction have experienced some changes over the years. Figure 7 shows the average net electricity flows on Italian main lines. ${ }^{13}$ CNOR, SICI and SARD are net importers, while CSUD and SUD act as a hub in the center and southern part of Italy, as play the role of both importer and exporter. NORD and ROSN are the main exporting regions that deliver electricity to CNOR, SUD and SICI. However, ROSN is a virtual generation zone used for balancing the system, thus the regions do not have a withdrawal point (buyer). In

\footnotetext{
${ }^{12}$ This is probably due to the fact that these countries have cheaper generation mix (nuclear).

13 Although the detailed statistics is not reported in this paper, the capacities of transmission lines are relatively constant over the years. SARD-CSUD is the only transmission line whose capacity has been reinforced in 2011, thanks to the installation of new submarine cables that started to operate in March 2011. CSUD-SUD connection has the biggest transmission line capacity, while SARD-CSUD and SICI-SUD are the most limited lines.
} 


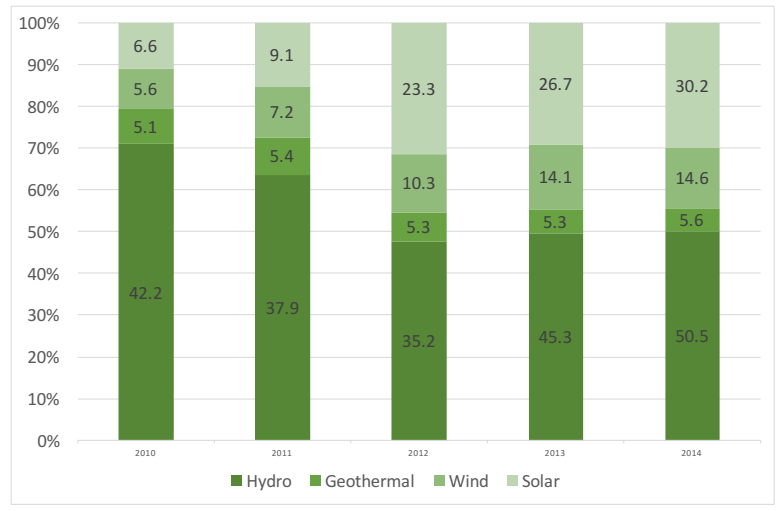
Figure 6: Renewable mix between 2010 and 2014 (Twh)

terms of quantity, CSUD-SUD connection registers the highest net average physical exchange, thus cementing CSUD position as the biggest importing zone in Italy. The imports are, however, gradually decreasing. Similar patterns can be observed in NORD-CNOR and ROSN-SUD, with larger decreases in import, $-76.2 \%$ for CNOR imports and $-50.8 \%$ for SUD imports. CNOR imports from CSUD have, instead, increased from 2010 to 2014. Transits from CSUD to SARD display the highest increase as the quantity more than doubled in 2014 compared to 2010, as a result of the new grid connection system. SICI import continues to increase at a rate of $76 \%$ over the whole period.

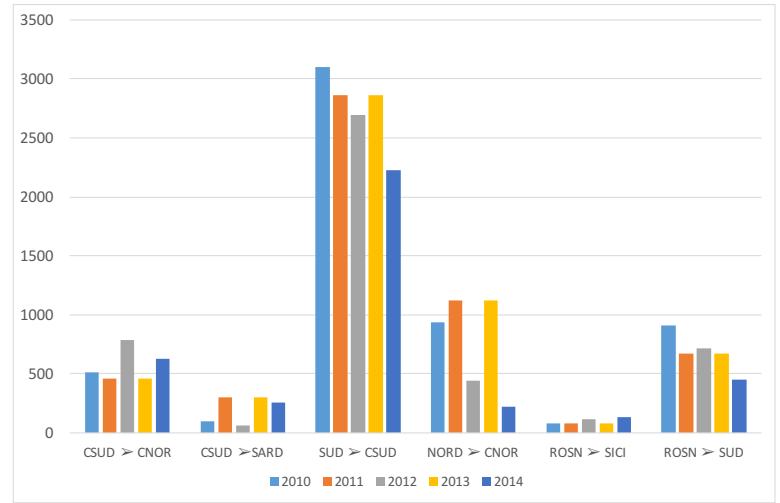

Figure 7: Average physical exchanges between the zones

By studying the series of zonal prices, we expect to detect a lasting price difference between importing and exporting neighbouring regions. We report the series of pairedprice differences for the period 2010-2014 in Figure 8 for the following pairs: CNORNORD; CNOR-CSUD; SARD-CSUD; CSUD-SUD; SICI-SUD. It is worthy to note that during the considered period the zonal prices of SUD and ROSN have differed 
for less than the $2 \%$ of the time, while the zonal price differences between SICISUD and SICI-ROSN have followed very similar patterns. This result allows us to consider SICI-SUD pair, which are formally non contiguous zones, instead of the two pairs SICI-ROSN and SUD-ROSN. For the pair CNOR and NORD we observe a substantial increase in the number of hours with negative price difference starting from 2012. This result seems to confirm that after a period characterized by a strong reliance on import from NORD, CNOR has reduced its importing needs. In CNORCSUD pair, CNOR has been an importer for most of the time, with rising frequency of positive price differences overtime. The graph also suggests that SARD generally imports from CSUD while the frequency of congestion between these two regions has decreased at the end of 2012 as shown by many hours of identical price. In CSUDSUD, where the first zone is always importing, we may detect a slightly decrease in the value of positive price differences. The series of price differences between SICI and SUD reveals that the negative price differences have decreased overtime while the positive have substantially remained constant.

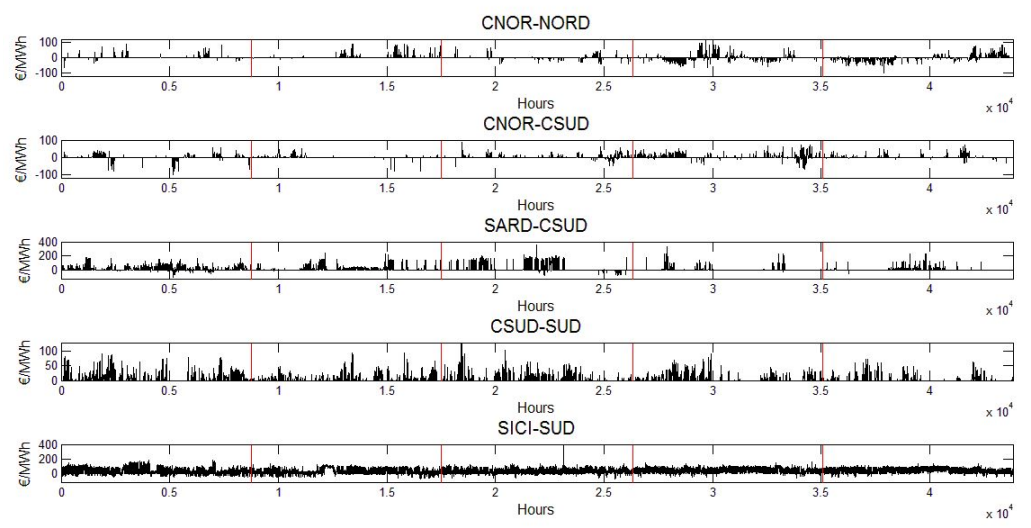

Figure 8: Series of zonal price differences, 2010-2014 Source: Authors' elaboration on GME

\section{The empirical setting and analysis}

Table 2 displays a general summary of GME bids' database. The average number of bids per year has reached the threshold of 8 billion in 2014, while the number of participating units has slightly decreased after 2012 .

The descriptive statistics of the series used in the multinomial logit model are reported in Tables 14 and 15 in Appendix B. The descriptive statistics for the series used in the 3 stage least square analysis are shown in Tables 16 and 17 in Appendix C. Demand and price series are directly collected from GME database. Supply series have been constructed by aggregating bid data to build the hourly market supply curves resulting from the market splitting algorithm. GME bids have than been matched with REF's database containing a mapping of power plants from bidding units to technology. The empirical models have been estimated on five zonal pairs using observations from 2010-2014 period. The five zonal pairs are: 


\begin{tabular}{rrr}
\hline & Number of bids & Number of units \\
\hline 2010 & 6975701 & 976 \\
2011 & 7149431 & 1257 \\
2012 & 7090579 & 1281 \\
2013 & 7737633 & 1152 \\
2014 & 8086282 & 1189 \\
\hline
\end{tabular}

Table 2: Database summary Source: Authors' elaboration on GME

\section{CNOR-NORD}

\section{CNOR-CSUD}

\section{SARD-CSUD}

4. CSUD-SUD

5. SICI-SUD

The first zone of the pair is generally an importing region.

\subsection{Multinomial logit model}

For each zonal pair (ZONE1-ZONE2) the dependent variable in the multinomial logit model, $y$, may assume three values: ${ }^{14}$

- $y=-1$ when the zonal price in ZONE1 is lower than the zonal price in ZONE2: in this case we say that there is "congestion from" ZONE1 (which is exporting power) or a "negative price difference";

- $y=0$ when the zonal prices in ZONE1 and ZONE2 are equal: in this case we say that there is "no congestion" (the flows between the two zones respect the transmission constraint) and hence no price difference;

- $y=1$ when the zonal price in ZONE1 exceeds the zonal price in ZONE2: in this case we say that there is "congestion to" ZONE1 (which is importing power) or a "positive price difference".

On average, the zonal prices of the neighboring zones paired for the five year period differ about $27 \%$ of the time; however, this figure hides a large heterogeneity (see Table 15 in Appendix B). If the link CNOR-NORD has been uncongested for $92 \%$ of the time, the zones SICI and SUD have registered the same price only $18 \%$ of the total hours. Quite surprisingly, congestion coming from CNOR have been more frequent that those coming from NORD, indicating a change in flows direction between these two zones. In CNOR-CSUD, CNOR confirms to be an importer with congestion to this region accounting for $7 \%$ of the hours, while most of the time the two zone have experienced no congestion ( $91 \%$ of the time). The lines SARD-CSUD and CSUD-SUD have followed similar patterns with congestion to the first zone occurring $15 \%$ and $16 \%$ of the time, respectively. The frequencies of no congestion have been also similar ( $83 \%$ and $85 \%$ of the time respectively). Is is worthy to note that while congestion from SARD to SUD has occurred, although quite rarely (1\% of the hours), CSUD

\footnotetext{
${ }^{14}$ CSUD-SUD pair is characterized by the occurrence of only two outcomes; in this case we estimate a logit model with a binary dependent variable.
} 
has never exported to SUD. Finally flows to SICI have congested the line SICI-SUD $75 \%$ of the time while flows from SICI have done so for $7 \%$ of the hours.

Fo each zonal pair we are going to estimate the following two equations:

$$
\begin{gathered}
\log \frac{\operatorname{Pr}(y=-1)}{\operatorname{Pr}(y=0)}=\alpha_{1}+\sum_{i=1}^{4} \eta_{i} \boldsymbol{Y}_{\boldsymbol{i}}+\sum_{r=1}^{4} \beta_{r} \boldsymbol{X}_{\boldsymbol{r}}+\epsilon \\
\log \frac{\operatorname{Pr}(y=1)}{\operatorname{Pr}(y=0)}=\alpha_{2}+\sum_{i=1}^{4} \eta_{i} \boldsymbol{Y}_{\boldsymbol{i}}+\sum_{r=1}^{4} \beta_{r} \boldsymbol{X}_{\boldsymbol{r}}+\epsilon
\end{gathered}
$$

where:

- $\alpha_{1,2}$ are the constants

- $\boldsymbol{Y}_{\boldsymbol{i}}$ is the matrix of yearly dummies

- $\boldsymbol{X}_{\boldsymbol{r}}$ is the matrix of regressors and includes:

- Hydro generation in the pairing zones (ZONE_Hydro)

- Wind generation in the pairing zones (ZONE_Wind)

- Photovoltaic generation in the pairing zones (ZONE_PV_tot)

- Demand in the pairing zones (ZONE_D)

\subsubsection{Multinomial logit results}

Estimation results are shown in Tables from 3 to $7 .{ }^{15}$ The second and the third columns report the results in terms of log-odds and marginal effects respectively when the congestion is from ZONE1 $(y=-1)$. The fourth and the fifth columns present the results in terms of log-odds and marginal effects when the congestion is to ZONE1 $(y=1)$.

\footnotetext{
${ }^{15}$ Standard errors are reported below the coefficients.
} 


\begin{tabular}{|c|c|c|c|c|}
\hline VARIABLES & Congestion from CNOR & $\mathrm{mfx}$ & Congestion to CNOR & $\mathrm{mfx}$ \\
\hline CNOR_Hydro & $\begin{array}{l}0.00269 * * * \\
-0.00019\end{array}$ & $\begin{array}{l}2.27 \mathrm{e}-05^{* * *} \\
-2.14 \mathrm{E}-06\end{array}$ & $\begin{array}{l}-0.00143^{* * *} \\
-0.00023\end{array}$ & $\begin{array}{c}-1.48 \mathrm{e}-05^{* * *} \\
-2.38 \mathrm{E}-06\end{array}$ \\
\hline CNOR_Wind & $\begin{array}{l}0.0286 * * * \\
-0.00213\end{array}$ & $\begin{array}{l}0.000240 * * * \\
-2.43 \mathrm{E}-05\end{array}$ & $\begin{array}{l}-0.00615^{*} \\
-0.00328\end{array}$ & $\begin{array}{l}-6.50 \mathrm{e}-05^{*} \\
-3.34 \mathrm{E}-05\end{array}$ \\
\hline CNOR_PV_Tot & $\begin{array}{l}0.00313^{* * *} \\
-0.00017\end{array}$ & $\begin{array}{l}2.68 \mathrm{e}-05^{* * *} \\
-2.39 \mathrm{E}-06\end{array}$ & $\begin{array}{l}-0.00622 * * * \\
-0.00047\end{array}$ & $\begin{array}{l}-6.36 \mathrm{e}-05^{* * *} \\
-4.53 \mathrm{E}-06\end{array}$ \\
\hline CNOR_D & $\begin{array}{l}-0.00223 * * * \\
-0.00012\end{array}$ & $\begin{array}{l}-1.89 \mathrm{e}-05^{* * * *} \\
-1.53 \mathrm{E}-06\end{array}$ & $\begin{array}{l}0.00295 * * * \\
-0.00011\end{array}$ & $\begin{array}{l}3.02 \mathrm{e}-05 * * * \\
-1.74 \mathrm{E}-06\end{array}$ \\
\hline NORD_Hydro & $\begin{array}{l}-0.000427^{* * *} \\
-2.67 \mathrm{E}-05\end{array}$ & $\begin{array}{c}-3.62 \mathrm{e}-06^{* * *} \\
-3.18 \mathrm{E}-07\end{array}$ & $\begin{array}{l}0.000508 * * * \\
-2.89 \mathrm{E}-05\end{array}$ & $\begin{array}{l}5.20 \mathrm{e}-06 * * * \\
-3.51 \mathrm{E}-07\end{array}$ \\
\hline NORD_Wind & $\begin{array}{l}0.0286^{* * *} \\
-0.00476\end{array}$ & $\begin{array}{l}0.000241 * * * \\
-4.30 \mathrm{E}-05\end{array}$ & $\begin{array}{l}-0.0139 * * \\
-0.00541\end{array}$ & $\begin{array}{l}-0.000144 * * * \\
-5.55 \mathrm{E}-05\end{array}$ \\
\hline NORD_PV_Tot & $\begin{array}{l}0.000148 * * * \\
-5.34 \mathrm{E}-05\end{array}$ & $\begin{array}{l}1.16 \mathrm{e}-06 * * * \\
-4.47 \mathrm{E}-07\end{array}$ & $\begin{array}{l}0.000929 * * * \\
-0.00012\end{array}$ & $\begin{array}{l}9.44 \mathrm{e}-06 * * * \\
-1.18 \mathrm{E}-06\end{array}$ \\
\hline NORD_D & $\begin{array}{c}0.000408 * * * \\
-1.82 \mathrm{E}-05\end{array}$ & $\begin{array}{l}3.45 \mathrm{e}-06 * * * \\
-2.70 \mathrm{E}-07\end{array}$ & $\begin{array}{l}-0.000463 * * * \\
-2.04 \mathrm{E}-05\end{array}$ & $\begin{array}{l}-4.75 \mathrm{e}-06^{* * *} \\
-3.00 \mathrm{E}-07\end{array}$ \\
\hline Year2 & $\begin{array}{l}-1.463 * * * \\
-0.345\end{array}$ & $\begin{array}{l}-0.00867 * * * \\
-0.00121\end{array}$ & $\begin{array}{c}0.537 * * * \\
-0.0883\end{array}$ & $\begin{array}{l}0.00658^{* * *} \\
-0.0013\end{array}$ \\
\hline Year3 & $\begin{array}{l}0.289^{*} \\
-0.168\end{array}$ & $\begin{array}{c}0.00268 \\
-0.00166\end{array}$ & $\begin{array}{l}-0.499 * * * \\
-0.145\end{array}$ & $\begin{array}{l}-0.00444 * * * \\
-0.00112\end{array}$ \\
\hline Year4 & $\begin{array}{l}-0.567 * * * \\
-0.168\end{array}$ & $\begin{array}{l}-0.00414^{* * *} \\
-0.0011\end{array}$ & $\begin{array}{c}0.928 * * * \\
-0.151\end{array}$ & $\begin{array}{c}0.0129 * * * \\
-0.0029\end{array}$ \\
\hline Year5 & $\begin{array}{l}-0.743 * * * \\
-0.188\end{array}$ & $\begin{array}{l}-0.00531 * * * \\
-0.00113\end{array}$ & $\begin{array}{c}1.935 * * * \\
-0.175\end{array}$ & $\begin{array}{c}0.0397 * * * \\
-0.00678\end{array}$ \\
\hline Constant & $\begin{array}{l}-5.183 * * * \\
-0.204\end{array}$ & & $\begin{array}{l}-7.917 * * * \\
-0.19\end{array}$ & \\
\hline Observations & 43,824 & 43,824 & 43,824 & 43,824 \\
\hline $\begin{array}{l}\text { Log-Lik Intercept Only: } \\
\text { D(43798): }\end{array}$ & $\begin{array}{l}-31133.193 \\
41760.267\end{array}$ & & $\begin{array}{c}\text { Log-Lik Full Model: } \\
\text { LR (24): } \\
\text { Prob > LR: }\end{array}$ & $\begin{array}{c}-20880.1 \\
20506.12 \\
0\end{array}$ \\
\hline McFadden's R2: & 0.329 & & McFadden's Adj R2: & 0.328 \\
\hline ML (Cox-Snell) R2: & $\begin{array}{l}0.374 \\
0.812\end{array}$ & & Cragg-Uhler(Nagelkerke)R2: & $\begin{array}{l}0.493 \\
0.253\end{array}$ \\
\hline $\begin{array}{l}\text { Count R2: } \\
\text { AIC: }\end{array}$ & $\begin{array}{l}0.812 \\
0.954\end{array}$ & & $\begin{array}{l}\text { Adj Count R2: } \\
\text { AIC*n: }\end{array}$ & $\begin{array}{c}0.253 \\
41812.27\end{array}$ \\
\hline BIC: & -426349.993 & & BIC': & -20249.6 \\
\hline BIC used by Stata: & 42038.154 & & AIC used by Stata: & 41812.27 \\
\hline
\end{tabular}

Table 3: Estimations for CNOR-NORD 


\begin{tabular}{|c|c|c|c|c|}
\hline VARIABLES & Congestion from CNOR & $\mathrm{mfx}$ & Congestion to CNOR & $\mathrm{mfx}$ \\
\hline CNOR_Hydro & $\begin{array}{l}0.00221 * * * \\
-0.00046\end{array}$ & $\begin{array}{l}1.13 \mathrm{e}-05 * * * \\
-2.43 \mathrm{E}-06\end{array}$ & $\begin{array}{l}0.000395^{*} \\
-0.00021\end{array}$ & $\begin{array}{l}1.83 \mathrm{e}-05^{*} \\
-9.82 \mathrm{E}-06\end{array}$ \\
\hline CNOR_Wind & $\begin{array}{l}0.0287 * * * \\
-0.00511\end{array}$ & $\begin{array}{c}0.000148^{* * *} \\
-2.73 \mathrm{E}-05\end{array}$ & $\begin{array}{l}-0.00225 \\
-0.00204\end{array}$ & $\begin{array}{l}-0.00012 \\
-9.77 \mathrm{E}-05\end{array}$ \\
\hline CNOR_PV_Tot & $\begin{array}{l}-0.00042 \\
-0.0012\end{array}$ & $\begin{array}{l}-2.10 \mathrm{E}-06 \\
-6.18 \mathrm{E}-06\end{array}$ & $\begin{array}{l}-0.00016 \\
-0.00025\end{array}$ & $\begin{array}{l}-7.29 \mathrm{E}-06 \\
-1.20 \mathrm{E}-05\end{array}$ \\
\hline CNOR_D & $\begin{array}{l}-0.00148 * * * \\
-0.00016\end{array}$ & $\begin{array}{l}-8.02 \mathrm{e}-06^{* * *} \\
-1.01 \mathrm{E}-06\end{array}$ & $\begin{array}{l}0.00160 * * * \\
-8.71 \mathrm{E}-05\end{array}$ & $\begin{array}{l}7.68 \mathrm{e}-05^{* * *} \\
-4.00 \mathrm{E}-06\end{array}$ \\
\hline CSUD_Hydro & $\begin{array}{c}-0.00199 * * * \\
-0.00054\end{array}$ & $\begin{array}{l}-1.05 \mathrm{e}-05^{* * *} \\
-2.84 \mathrm{E}-06\end{array}$ & $\begin{array}{c}0.000799 * * * \\
-0.00024\end{array}$ & $\begin{array}{l}3.87 \mathrm{e}-05^{* * *} \\
-1.16 \mathrm{E}-05\end{array}$ \\
\hline CSUD_Wind & $\begin{array}{c}-0.00479 * * * \\
-0.00048 \\
\end{array}$ & $\begin{array}{c}-2.56 \mathrm{e}-05^{* * *} \\
-2.52 \mathrm{E}-06\end{array}$ & $\begin{array}{c}0.00355 * * * \\
-0.00011\end{array}$ & $\begin{array}{l}0.000171 * * * \\
-5.18 \mathrm{E}-06\end{array}$ \\
\hline CSUD_PV_Tot & $\begin{array}{c}-0.00186^{*} \\
-0.00099\end{array}$ & $\begin{array}{l}-9.80 \mathrm{e}-06^{*} \\
-5.11 \mathrm{E}-06\end{array}$ & $\begin{array}{c}0.000900 * * * \\
-0.00021\end{array}$ & $\begin{array}{c}4.36 \mathrm{e}-05 * * * \\
-1.01 \mathrm{E}-05\end{array}$ \\
\hline CSUD_D & $\begin{array}{l}0.00144 * * * \\
-0.00012\end{array}$ & $\begin{array}{l}7.78 \mathrm{e}-06 * * * \\
-7.98 \mathrm{E}-07\end{array}$ & $\begin{array}{l}-0.00150 * * * \\
-6.52 \mathrm{E}-05\end{array}$ & $\begin{array}{l}-7.21 \mathrm{e}-05^{* * *} \\
-2.93 \mathrm{E}-06\end{array}$ \\
\hline Year2 & $\begin{array}{l}-2.444^{* * *} \\
-0.248\end{array}$ & $\begin{array}{l}-0.00759 * * * \\
-0.00062\end{array}$ & $\begin{array}{l}-0.636 * * * \\
-0.0724\end{array}$ & $\begin{array}{l}-0.0256 * * * \\
-0.0025\end{array}$ \\
\hline Year3 & $\begin{array}{l}-0.338 * * * \\
-0.13\end{array}$ & $\begin{array}{l}-0.00154 * * * \\
-0.00057\end{array}$ & $\begin{array}{c}-0.183^{* *} \\
-0.0711\end{array}$ & $\begin{array}{l}-0.00827 * * * \\
-0.00309\end{array}$ \\
\hline Year4 & $\begin{array}{l}0.0498 \\
-0.125\end{array}$ & $\begin{array}{l}0.000375 \\
-0.00067 \\
\end{array}$ & $\begin{array}{c}-0.485 * * * \\
-0.0766\end{array}$ & $\begin{array}{l}-0.0205 * * * \\
-0.00283\end{array}$ \\
\hline Year5 & $\begin{array}{l}-0.660 * * * \\
-0.169\end{array}$ & $\begin{array}{c}-0.00262 * * * \\
-0.00065\end{array}$ & $\begin{array}{l}-1.531 * * * \\
-0.0904\end{array}$ & $\begin{array}{l}-0.0518^{* * *} \\
-0.00224\end{array}$ \\
\hline Constant & $\begin{array}{l}-5.299 * * * \\
-0.261\end{array}$ & & $\begin{array}{l}-1.382 * * * \\
-0.125\end{array}$ & \\
\hline Observations & 43,824 & 43,824 & 43,824 & 43,824 \\
\hline $\begin{array}{l}\text { Log-Lik Intercept Only: } \\
\text { D(43798): }\end{array}$ & $\begin{array}{l}-14607.4 \\
25280.78\end{array}$ & & $\begin{array}{l}\text { Log-Lik Full Model: } \\
\text { LR(24): } \\
\text { Prob > LR: }\end{array}$ & $\begin{array}{c}-12640.4 \\
3934.012 \\
0\end{array}$ \\
\hline McFadden's R2: & 0.135 & & McFadden's Adj R2: & 0.133 \\
\hline $\begin{array}{l}\text { ML (Cox-Snell) R2: } \\
\text { Count R2: }\end{array}$ & $\begin{array}{l}0.086 \\
0.913\end{array}$ & & $\begin{array}{c}\text { Cragg-Uhler(Nagelkerke) } \\
\text { Adj Count R2: }\end{array}$ & $\begin{array}{l}\text { R2: } 0.176 \\
-0.008\end{array}$ \\
\hline AIC: & 0.578 & & AIC*n: & 25332.78 \\
\hline BIC: & -442829 & & BIC': & -3677.5 \\
\hline BIC used by Stata: & 25558.66 & & AIC used by Stata: & 25332.78 \\
\hline
\end{tabular}

Table 4: Estimations for CNOR-CSUD 


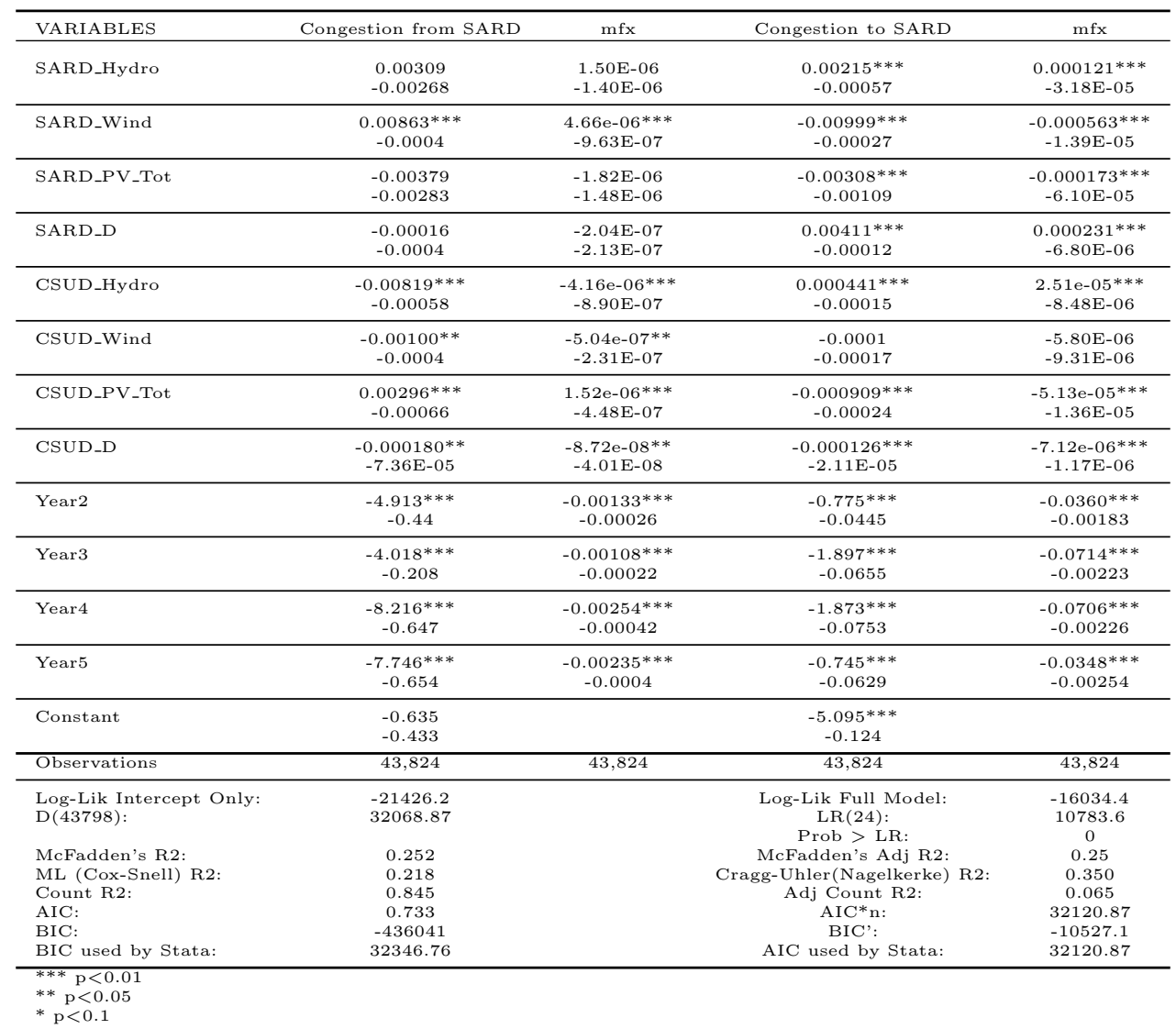

Table 5: Estimations for SARD-CSUD 


\begin{tabular}{|c|c|c|c|c|}
\hline VARIABLES & Congestion from CSUD & $\mathrm{mfx}$ & Congestion to CSUD & $\mathrm{mfx}$ \\
\hline CSUD_Hydro & & & $\begin{array}{l}0.00143 * * * \\
-0.00015\end{array}$ & $\begin{array}{l}0.000103 * * * \\
-1.05 \mathrm{E}-05\end{array}$ \\
\hline CSUD_Wind & & & $\begin{array}{l}0.00114^{* * *} \\
-0.00019\end{array}$ & $\begin{array}{l}8.23 \mathrm{e}-05^{* * *} \\
-1.36 \mathrm{E}-05\end{array}$ \\
\hline CSUD_PV_Tot & & & $\begin{array}{l}0.000270^{* *} \\
-0.00013\end{array}$ & $\begin{array}{l}1.94 \mathrm{e}-05^{* *} \\
-9.20 \mathrm{E}-06\end{array}$ \\
\hline CSUD_D & & & $\begin{array}{l}0.00128 * * * \\
-3.32 \mathrm{E}-05\end{array}$ & $\begin{array}{l}9.20 \mathrm{e}-05 * * * \\
-2.43 \mathrm{E}-06\end{array}$ \\
\hline SUD_Hydro & & & $\begin{array}{c}0.000601 * * * \\
-0.00012\end{array}$ & $\begin{array}{l}4.33 \mathrm{e}-05 * * * \\
-8.85 \mathrm{E}-06\end{array}$ \\
\hline SUD_Wind & & & $\begin{array}{c}0.000706^{* * *} \\
-8.88 \mathrm{E}-05\end{array}$ & $\begin{array}{l}5.09 \mathrm{e}-05^{* * *} \\
-6.42 \mathrm{E}-06\end{array}$ \\
\hline SUD_PV_Tot & & & $\begin{array}{l}0.00126 * * * \\
-7.93 \mathrm{E}-05\end{array}$ & $\begin{array}{l}9.09 \mathrm{e}-05 * * * \\
-5.79 \mathrm{E}-06\end{array}$ \\
\hline SUD_D & & & $\begin{array}{c}-0.00109 * * * \\
-6.55 \mathrm{E}-05\end{array}$ & $\begin{array}{c}-7.88 \mathrm{e}-05^{* * *} \\
-4.79 \mathrm{E}-06\end{array}$ \\
\hline Year2 & & & $\begin{array}{l}-0.558 * * * \\
-0.0451\end{array}$ & $\begin{array}{l}-0.0351 * * * \\
-0.00251\end{array}$ \\
\hline Year3 & & & $\begin{array}{l}-1.043^{* * *} \\
-0.055\end{array}$ & $\begin{array}{l}-0.0591 * * * \\
-0.00248\end{array}$ \\
\hline Year4 & & & $\begin{array}{l}-1.910^{* * *} \\
-0.0697\end{array}$ & $\begin{array}{l}-0.0925 * * * \\
-0.00248\end{array}$ \\
\hline Year5 & & & $\begin{array}{l}-1.405^{* * *} \\
-0.077\end{array}$ & $\begin{array}{l}-0.0742 * * * \\
-0.00305\end{array}$ \\
\hline Constant & & & $\begin{array}{l}-6.927^{* * *} \\
-0.119\end{array}$ & \\
\hline Observations & 0 & 0 & 43,824 & 43,824 \\
\hline $\begin{array}{l}\text { Log-Lik Intercept Only: } \\
\text { D(43811): }\end{array}$ & $\begin{array}{l}-18641.31 \\
28331.303\end{array}$ & & $\begin{array}{l}\text { Log-Lik Full Model: } \\
\text { LR(12): } \\
\text { Prob > LR: }\end{array}$ & $\begin{array}{c}-14165.7 \\
8951.316 \\
0\end{array}$ \\
\hline $\begin{array}{l}\text { McFadden's R2: } \\
\text { ML (Cox-Snell) R2: }\end{array}$ & $\begin{array}{c}0.24 \\
0.185\end{array}$ & & $\begin{array}{c}\text { McFadden's Adj R2: } \\
\text { Crag-Uhler(Nagelkerke) }\end{array}$ & $\begin{array}{l}0.239 \\
0.2322\end{array}$ \\
\hline $\begin{array}{l}\text { ML (Cox-Snell) R2: } \\
\text { Count R2: }\end{array}$ & $\begin{array}{l}0.185 \\
0.859\end{array}$ & & $\begin{array}{l}\text { Cragg-Uhler(Nagelkerke) } \\
\text { Adj Count R2: }\end{array}$ & $\begin{array}{c}\mathrm{R} 2: 0.322 \\
0.067\end{array}$ \\
\hline AIC: & 0.647 & & AIC*n: & 28357.3 \\
\hline BIC: & -439917.9 & & BIC': & -8823.06 \\
\hline BIC used by Stata: & 28470.246 & & AIC used by Stata: & 28357.3 \\
\hline
\end{tabular}

Table 6: Estimations for CSUD-SUD 


\begin{tabular}{|c|c|c|c|c|}
\hline VARIABLES & Congestion from SICI & $\mathrm{mfx}$ & Congestion to SICI & $\mathrm{mfx}$ \\
\hline SICI_Hydro & $\begin{array}{l}0.0109^{* * *} \\
-0.0019\end{array}$ & $\begin{array}{c}0.000402^{* * *} \\
-3.68 \mathrm{E}-05\end{array}$ & $\begin{array}{l}-0.0118 * * * \\
-1.31 \mathrm{E}-03\end{array}$ & $\begin{array}{l}-0.00146 * * * \\
-0.000136\end{array}$ \\
\hline SICI_Wind & $\begin{array}{l}0.00198 * * * \\
-0.000126\end{array}$ & $\begin{array}{c}0.000133^{* * *} \\
-4.53 \mathrm{E}-06\end{array}$ & $\begin{array}{l}-0.00570 * * * \\
-9.30 \mathrm{E}-05\end{array}$ & $\begin{array}{l}-0.000652^{* * * *} \\
-1.05 \mathrm{E}-05\end{array}$ \\
\hline SICI_PV_Tot & $\begin{array}{l}0.000965^{* *} \\
-0.000484\end{array}$ & $\begin{array}{l}0.000111^{* * *} \\
-9.54 \mathrm{E}-06\end{array}$ & $\begin{array}{l}-0.00553 * * * \\
-2.83 \mathrm{E}-04\end{array}$ & $\begin{array}{c}-0.000616^{* * *} \\
-2.98 \mathrm{E}-05\end{array}$ \\
\hline SICI_D & $\begin{array}{l}-0.00169 * * * \\
-0.000181\end{array}$ & $\begin{array}{l}-0.000114^{* * *} \\
-4.68 \mathrm{E}-06\end{array}$ & $\begin{array}{l}0.00487 * * * \\
-1.16 \mathrm{E}-04\end{array}$ & $\begin{array}{l}0.000557^{* * *} \\
-1.25 \mathrm{E}-05\end{array}$ \\
\hline SUD_Hydro & $\begin{array}{l}-0.00132 * * * \\
-0.000193\end{array}$ & $\begin{array}{l}-3.81 \mathrm{e}-05^{* * *} \\
-3.64 \mathrm{E}-06\end{array}$ & $\begin{array}{c}0.000793^{* * *} \\
-1.16 \mathrm{E}-04\end{array}$ & $\begin{array}{l}0.000108^{* * *} \\
-1.20 \mathrm{E}-05\end{array}$ \\
\hline SUD_Wind & $\begin{array}{l}-0.000754^{* * *} \\
-8.59 \mathrm{E}-05\end{array}$ & $\begin{array}{c}-2.17 \mathrm{e}-05^{* * *} \\
-1.71 \mathrm{E}-06\end{array}$ & $\begin{array}{c}0.000447 * * * \\
-5.08 \mathrm{E}-05\end{array}$ & $\begin{array}{l}6.11 \mathrm{e}-05 * * * \\
-5.34 \mathrm{E}-06\end{array}$ \\
\hline SUD_PV_Tot & $\begin{array}{c}-0.000643 * * * \\
-0.000173\end{array}$ & $\begin{array}{c}-3.00 \mathrm{e}-05^{* * *} \\
-3.32 \mathrm{E}-06\end{array}$ & $\begin{array}{l}0.00106 * * * \\
-9.74 \mathrm{E}-05\end{array}$ & $\begin{array}{c}0.000126^{* * *} \\
-1.02 \mathrm{E}-05\end{array}$ \\
\hline SUD_D & $\begin{array}{c}0.000722^{* * *} \\
-0.000127\end{array}$ & $\begin{array}{l}2.03 \mathrm{e}-05^{* * *} \\
-2.43 \mathrm{E}-06\end{array}$ & $\begin{array}{c}-0.000397^{* * *} \\
-7.89 \mathrm{E}-05\end{array}$ & $\begin{array}{l}-5.52 \mathrm{e}-05^{* * *} \\
-8.17 \mathrm{E}-06\end{array}$ \\
\hline Year2 & $\begin{array}{r}0.0642 \\
-0.0605\end{array}$ & $\begin{array}{c}-0.00661 * * * \\
-0.000968\end{array}$ & $\begin{array}{c}0.503 * * * \\
-0.0461\end{array}$ & $\begin{array}{l}0.0479 * * * \\
-0.00385\end{array}$ \\
\hline Year3 & $\begin{array}{l}0.195 * * * \\
-0.0747\end{array}$ & $\begin{array}{l}-0.0205 * * * \\
-0.000951\end{array}$ & $\begin{array}{c}1.942 * * * \\
-0.0552\end{array}$ & $\begin{array}{l}0.142 * * * \\
-0.003\end{array}$ \\
\hline Year4 & $\begin{array}{l}-0.772^{* * *} \\
-0.105 \\
\end{array}$ & $\begin{array}{c}-0.0359 * * * \\
-0.00135\end{array}$ & $\begin{array}{c}3.014 * * * \\
-0.0649 \\
\end{array}$ & $\begin{array}{l}0.198^{* * *} \\
-0.0032\end{array}$ \\
\hline Year5 & $\begin{array}{l}-0.708^{* * *} \\
-0.105\end{array}$ & $\begin{array}{l}-0.0399 * * * \\
-0.0015\end{array}$ & $\begin{array}{l}3.700 * * * \\
-0.0709\end{array}$ & $\begin{array}{l}0.226 * * * \\
-0.00346\end{array}$ \\
\hline Constant & $\begin{array}{c}0.333 * * \\
-0.152\end{array}$ & & $\begin{array}{l}-7.747 * * * \\
-0.118\end{array}$ & \\
\hline Observations & 43,824 & 43,824 & 43,824 & 43,824 \\
\hline $\begin{array}{l}\text { Log-Lik Intercept Only: } \\
\text { D(43798): }\end{array}$ & $\begin{array}{r}-31133.193 \\
41760.267\end{array}$ & & $\begin{array}{c}\text { Log-Lik Full Model: } \\
\text { LR }(24): \\
\text { Prob > LR: }\end{array}$ & $\begin{array}{l}-20880.1 \\
20506.12 \\
0\end{array}$ \\
\hline McFadden's R2: & 0.329 & & McFadden's Adj R2: & 0.328 \\
\hline $\begin{array}{l}\text { ML (Cox-Snell) R2: } \\
\text { Count R2: }\end{array}$ & $\begin{array}{l}0.374 \\
0.812\end{array}$ & & $\begin{array}{c}\text { Cragg-Uhler(Nagelkerke)R2: } \\
\text { Adj Count R2: }\end{array}$ & $\begin{array}{l}0.493 \\
0.253\end{array}$ \\
\hline AIC: & 0.954 & & AIC*n: & 41812.27 \\
\hline BIC: & -426349.993 & & BIC': & -20249.6 \\
\hline BIC used by Stata: & 42038.154 & & AIC used by Stata: & 41812.27 \\
\hline
\end{tabular}

Table 7: Estimation for SICI-SUD 

that: ${ }^{16}$

When congestion is coming from ZONE1 (second and third columns) we observe

1) In ZONE1:

- Rising wind production increases the probability of congestion in all pairs;

- Rising solar production increases the probability of congestion in CNORNORD and SICI-SUD pairs (the coefficient is not significant in CNOR-CSUD and SARD-CSUD pairs);

- Rising hydro production increases the probability of congestion in all pairs with the exception of SARD-CSUD (probably due to the scarce hydro production in SARD)

- Rising the demand decreases likelihood of congestion (with the exception of SARD where the coefficient is not significant)

2) In ZONE2:

- Rising wind production decreases the probability of congestion in all pairs except in CNOR-NORD (where wind production in NORD seems to increase congestion);

- Rising solar production decreases the probability of congestion in CNORCSUD and in SICI-SUD pairs (while it increases congestion in CNOR-NORD and SARD-CSUD);

- Rising hydro production decreases the probability of congestion in all pairs;

- Rising the demand in ZONE2 increases the probability of congestion in all pairs.

These results indicate that a larger renewable generation in ZONE1 is associated with an increase in the relative log odds of a congestion coming from ZONE1 with respect to no congestion due to improved export possibilities. A larger RES production in ZONE2 on the contrary decreases the likelihood of congestion from ZONE1 since less import are needed. An opposite reasoning works for the demand: when the demand is larger in ZONE1 there is less export, therefore less probability of congestion from ZONE1. The reverse is true when the demand rises in ZONE2 since more import are needed and hence the probability of congestion from ZONE1 increases.

The results in terms of marginal effects allow to directly quantify the impact of each regressor on the probability of congestion. Marginal effect coefficients indicate how the probability of an outcome increases when the regressor increases by a megawatt hours, all the other regressors kept at their average. For example, in CNOR-NORD pair the value of the coefficient associated to wind generation in CNOR indicates that a Mwh increase in generation raises by $0.024 \%$ the probability of a congestion from CNOR (ZONE1) to NORD (ZONE2).

We expect to observe results of opposite sign when we study congestion to ZONE1 (fourth and fifth columns). In this case the estimations unveil that:

1) In ZONE1:

- Rising wind production decreases the probability of congestion in all pairs with the exception of CNOR-CSUD (where the coefficient on wind is not significant) and of CSUD-SUD where a larger wind supply in ZONE1 seems to increase the congestion in entry;

\footnotetext{
${ }^{16}$ Note that in CSUD-SUD pair there are never negative price differences.
} 
- Rising solar production decreases the probability of congestion in CNORNORD, SARD-CSUD and SICI-SUD pairs (the coefficient is not significant in CNOR-CSUD and it is again positive in CSUD-SUD);

- Rising hydro production decreases the probability of congestion in CNORNORD and SICI-SUD pairs (in CNOR-CSUD the coefficient is not significant and its is positive in SARD-CSUD and CSUD-SUD);

- Rising the demand increases likelihood of congestion in all pairs;

2) In ZONE2:

- Rising wind production increases the probability of congestion in all pairs except in CNOR-NORD (where wind production in NORD seems to decrease congestion and in SARD-CSUD where the regressor is not significant);

- Rising solar production increases the probability of congestion in all pairs with the exception of SARD-CSUD;

- Rising hydro production increases the probability of congestion in all pairs;

- Rising the demand in ZONE2 decreases the probability of congestion in all pairs.

The results for congestion to ZONE1 seem to validate the conclusions drawn in the case of congestion from ZONE1. When ZONE1 is importing power, a larger renewable generation in ZONE1 reduces importing needs and thus the relative log odds of a congestion to ZONE1 with respect to no congestion. A larger RES production in ZONE2 on the contrary increases the likelihood of congestion to ZONE1 due to the improved export possibilities. An opposite pattern is again followed by the demand: when the demand is larger in ZONE1 there is more need to import, therefore a higher probability of congestion to ZONE1. Finally, when the demand rises in ZONE2 less production can be exported and as a consequence the probability of causing a congestion to ZONE1 decreases. In terms of marginal effect, we observe for instance that in CNOR-NORD pair the value of the coefficient associated to wind generation in CNOR indicates that a Mwh increase in generation decreases by $0.0065 \%$ the probability of a congestion to CNOR (ZONE1).

Thanks to the symmetry, the results can be easily summarized (Table 8 ). Increasing renewable production in a zone increases the likelihood of causing a congestion to the neighboring zone, due to larger export possibilities. At the same time, a larger local supply reduces import needs thus decreasing the likelihood of suffering congestion in entry. Increasing local demand has an opposite effect: it lowers export possibilities, thus decreasing the probability of causing congestion in exit, and it raises import needs, therefore increasing the probability of suffering congestion in entry. It is worthy to note that these results hold for both importing and exporting regions. However, the importing regions are less likely to produce congestion in exit and more likely to suffer congestion in entry. Therefore a larger RES production in these regions is expected to bring more balances in flows between regions, while a larger RES production in exporting zones may exacerbate the problem of congestion.

\begin{tabular}{lllll}
\hline & Wind & PV & Hydro & Demand \\
\hline \multirow{2}{*}{ Congestion from ZONE1 } & ZONE1: $\uparrow$ & ZONE1: $\uparrow$ & ZONE1: $\uparrow$ & ZONE1: $\downarrow$ \\
& ZONE2: $\downarrow$ & ZONE2: $\downarrow$ & ZONE2: $\downarrow$ & ZONE2: $\uparrow$ \\
\hline \multirow{2}{*}{ Congestion to ZONE1 } & ZONE1: $\downarrow$ & ZONE1: $\downarrow$ & ZONE1: $\downarrow$ & ZONE1: \\
& ZONE2: $\uparrow$ & ZONE2: $\uparrow$ & ZONE2: $\uparrow$ & ZONE2: $\downarrow$ \\
\hline
\end{tabular}

Table 8: Multinomial logit result summary 


\subsection{Stage least square model}

Having understood the impact of RES production and demand on the probability of congestion, we extend our research to capture their effect on congestion cost. Congestion cost is paid by both IPEX participants and producers with bilateral contracts. In the day-ahead market, all participants pay an implicit congestion cost (ICC) per Mwh of net electricity flow through GME ${ }^{17}$, which is calculated based on the price difference

$$
\text { ZONE1_ZONE2 }=P_{Z O N E 1}-P_{Z O N E 2}
$$

$P_{Z O N E 1}$ is the zonal price of the importing zone and $P_{Z O N E 2}$ is the zonal price of the exporting zone. The larger the difference between the zonal prices of the neighboring regions, the larger the implicit congestion cost is. Producers with bilateral contract pay instead an explicit congestion cost called Corrispettivo per l'assegnazione dei diritti di utilizzo della capacità di trasporto (CCT). The explicit congestion cost (CCT) per MWh is calculated as:

$$
C C T_{z o n e}=P_{z o n e}-P U N
$$

where PUN is the the National Single Price. If the bilateral producer is in an exporting region, the $\mathrm{CCT}$ is negative $\left(P_{Z \text { one }}<P U N\right)$ meaning that the producer should pay the congestion cost. On the contrary, if the CCT is positive it is the network operator who pays the fee to the bilateral producer. The larger the difference between the zonal price and the PUN, the larger the CCT is.

Both CCT and ICC appear to be non-normally distributed based on Jarque-Bera test. In terms of level, CCT in SICI displays the highest positive mean followed by CCT in SARD. The positive mean values of CCT indicate that SICI and SARD are net importers since their zonal price is frequently higher than the PUN. It also shows that less-efficient production units are mainly utilized in these regions. CCT in SUD, on the other hand, registers the lowest mean followed by CSUD, CNOR and NORD. Hence, these zones have the most efficient and least-cost productions. In the case of the ICC, the means in SICI-SUD display the highest value with SARD-CSUD quite far behind. Hence, both transmission lines can be considered as the two most expensive lines in terms of congestion cost. They are frequently congested and only a small portion of efficient supply in the importing zone can be used for balancing the system. Transmission lines in CSUD-SUD, CNOR-NORD and CNOR-CSUD are ranked third, fourth and fifth from the most expensive transmission line, respectively.

Unlike in Woo et al. (2011), in order to to capture the Italian power exchange specificities we use 3SLS method instead of only OLS. In the first stage of 3SLS, we attempt to attack endogeneity problems of hydro in order to avoid bias in the estimation. Unlike renewable-energy supply, hydro production can be adjusted depending on the weather and portfolio optimization since it can be stored. In run-of-river hydro, a poundage is generally present for short term reserve whereas hydro with pumping technology is operated fully on the price arbitrage. ${ }^{18}$ Hence, their output cannot be considered as fully exogenous varoanles. In this study, we use lagged hydro production as the instrument variables for hydro production. ${ }^{19}$ We select $t-1, t-24$ and $t-168$ since the hydro production has daily seasonality, weekly seasonality and depends on

\footnotetext{
${ }^{17}$ Terna receives congestion cost payment from the offset of purchase and sales value of GME. Hence, they implicitly charge operational cost of managing transmission line to all stakeholders in IPEX.

${ }^{18}$ Note that pumping hydro is not considered renewable as run-of-river hydro.

${ }^{19}$ Due to lower frequency in weather data, we avoid using weather in our instrument variables.
} 
the production of the hour before. Hence, our first-stage regression equation can be formulated as follows.

$$
\hat{H}_{t}=\theta+\eta_{1} H_{t-1}+\eta_{2} H_{t-24}+\eta_{3} H_{t-168}
$$

Where, $\hat{H}_{t}$ is the fitted value of hydro production at time $t$ and $\theta$ is a constant.

Seemingly Unrelated Regressions (SUR) in the latter stage of our 3SLS is aimed to capture the impact of renewable while capturing the co-movement in multiple congestion costs. For the case of CCT, there are six congestion cost regressions, which represent each zone in Italy. In the case of ICC, there are five congestion cost regressions representing the connection between zones. For both CCT and ICC, each regression has the same general equation as follows.

$$
y=\alpha+\sum_{i=1}^{i=23} \delta_{i} h_{i}+\tau T+\beta(D-\hat{H}-R)+\kappa \hat{H} R+e
$$

Where, $y$ can be CCT or ICC, $\alpha$ is a constant, $h$ is hourly dummy variables, $T$ is the time trend, $R, H$, and $D$ are vectors of renewable production, fitted hydro supply, and demand respectively. Then, $\beta$ is a vector of coefficients of the difference between demand and renewables and $\kappa$ is a vector of coefficients of the interaction between renewable and hydro. In the case of $\mathrm{CCT}$, the vectors consist of production/consumption from the zone and the sum on rest of Italy. As for the ICC, the vectors consist only variables from ZONE1 (generally importing zone) and ZONE2 (generally exporting zone). ${ }^{20}$ Statistics estimations of high frequency data such as hourly electricity price require extra care from researchers as heteroskedsticity in the regression could provide bias in error estimation. Therefore, the estimation of the 3SLS is done under Feasible Generalized Least Square (FGLS) method since it can optimize the coefficient estimations of SUR whose true covariance matrix is unknown. This method is going to be used for treating unknown form of heteroskdasticity and autocorrelation that may present in the SUR disturbances (see Greene (2012)).

\subsection{SLS Result}

Before going into details of each estimations, we report the results the correlation errors matrix as a result of SUR estimation (see Table 9). First, let us look into the location effect on the two extreme, NORD and SICI. We may observe more negative correlation on the south direction (from top to bottom). Therefore, whenever CCT decreases in the NORD the CCT will increase in the south. This result can be explained as NORD is generally the main exporter and SICI is generally the main importer. Excessive supply from the North provides congestion, which subsequently creates lower zonal price and lower CCT. This excessive supply is transferred across Italy towards south. As a result, it increases the zonal price of the Southern region, which subsequently produces higher CCT in these zones. Second, big positive correlation is shown in the main connections especially, CNOR-CSUD and SARD-CSUD. This positive value indicates the same direction of increase/decrease in the CCT. This can only be explained if these zones are often converging into only one zone.

In the case of the ICC, the SUR estimation shows that the variables only have very small correlations as all of the values are close to zero (see table 10). Hence, the

\footnotetext{
${ }^{20}$ Constant, time trend, and hourly dummy variables are deterministic trend with a purpose of avoiding spurious regression. We run stationarity test on the regressors in order to determine these deterministic trend. The stationarity test can be found in Appendix D.
} 
variables and regressions are close to perfectly independent or unrelated. However, residuals from CNORD-NORD and CSUD-SUD seems to have small correlation (> 0.1). In addition, the estimation results through OLS show inconsistent numerical coefficient compared to SUR. Therefore, the regressions can still be considered as one system, but with very small correlation between each other.

\begin{tabular}{rrrrrrr}
\hline NORD & CNOR & CSUD & SARD & SUD & SICI & \\
\hline 1 & 0.081 & -0.371 & -0.375 & -0.356 & -0.601 & NORD \\
& 1 & 0.414 & -0.175 & 0.04 & -0.449 & CNOR \\
& & 1 & -0.002 & 0.412 & -0.298 & CSUD \\
& & & 1 & -0.067 & -0.05 & SARD \\
& & & & 1 & -0.094 & SUD \\
& & & & 1 & SICI \\
\hline
\end{tabular}

Table 9: Error correlation matrix CCT

\begin{tabular}{rrrrrr}
\hline CNOR_NORD & CNOR_CSUD & SARD_CSUD & CSUD_SUD & SICI_SUD & \\
\hline \multirow{2}{*}{1} & 0.056 & -0.042 & 0.166 & -0.048 & CNOR_NORD \\
& 1 & 0.022 & -0.089 & 0.038 & CNOR_CSUD \\
& & 1 & -0.012 & 0.052 & SARD_CSUD \\
& & & 1 & 0.077 & CSUD_SUD \\
& & & & 1 & SICI_SUD \\
\hline
\end{tabular}

Table 10: Error correlation matrix of ICC

Tthe estimation of CCT shown in table 11 below. The coefficients of $D H R \_Z O N E$ and $H R_{-} Z O N E$ provide us further insight into the market mechanism.

1) In a given zone:

- Coefficients of $D H R_{-} Z O N E$ suggest that increasing demand or lower renewable or hydro increase the congestion cost;

- SARD, SICI and SUD have the highest impact as it can increase the congestion cost for $0.0063 €, 0.0062$ €and $0.002 €$ €per Mwh increase in demand (or decrease in renewable);

- $H R_{-} Z O N E$ imply that larger hydro coupled with larger renewable production could decrease the congestion cost much further towards negative value (NORD is the only exception);

- SICI, SARD and SUD have the highest impact as it can further decrease the congestion cost for $0.0001 €, 0.0000064 €$ €and $0.0000052 €$ €per Mwh increase in renewable coupled with hydro;

2) outside the given zone:

- Coefficients of DHR_Italy_ZONE show that increasing demand or lower renewable or hydro decrease the congestion cost;

- Case of CSUD, NORD and SARD have the highest impact as it can decrease the congestion cost for $0.00044 €, 0.00036$ €and $0.0003 €$ €per Mwh increase in demand (or decrease in renewable) ;

- HR_Italy_ZONE suggest that larger hydro coupled with larger renewable in NORD, SICI and SARD could increase the congestion cost much further towards positive value (SUD, CSUD and CNOR display decreasing impact on congestion cost);

- Case of SICI and SARD have the highest impact as it can further increase the congestion cost for 0.000095 €and 0.000023 per 1000 Mwh increase in renewable and hydro. 


\begin{tabular}{|c|c|c|c|c|c|}
\hline Dependent & variable: & CCT_SUD & Dependent & variable: & CCT_NORD \\
\hline & Coefficient & p-value & & Coefficient & p-value \\
\hline DHRhat_SUD & 0.00206049 & $* * *$ & DHRhat_NORD & 0.0002593 & $* * *$ \\
\hline DHRhat_Italy_SUD & -0.00044484 & $* * *$ & DHRhat_Italy_NORD & -0.00036395 & *** \\
\hline HRhat_SUD & $-5.12 \mathrm{E}-06$ & $* * *$ & HRhat_NORD & $2.81 \mathrm{E}-08$ & *** \\
\hline HRhat_Italy_SUD & $-7.17 \mathrm{E}-08$ & $* * *$ & HRhat_Italy_NORD & $1.44 \mathrm{E}-07$ & $* * *$ \\
\hline SSR & 2855819 & & SSR & 674897.3 & \\
\hline S.E of regression & 8.088042 & & S.E of regression & 3.931849 & \\
\hline R-squared & 0.184087 & & R-squared & 0.28654 & \\
\hline Dependent & variable: & CCT_SICI & Dependent & variable: & CCT_CSUD \\
\hline & Coefficient & $\mathrm{p}$-value & & Coefficient & $\mathrm{p}$-value \\
\hline $\begin{array}{l}\text { DHRhat_SICI } \\
\text { DHRhat_Italy_SICI }\end{array}$ & & $\begin{array}{l}* * * \\
* * *\end{array}$ & $\begin{array}{l}\text { DHRhat_CSUD } \\
\text { DHR }\end{array}$ & 0.0015636 & $\begin{array}{l}* * * \\
* * *\end{array}$ \\
\hline $\begin{array}{r}\text { DHRhat_Italy_SICI } \\
\text { HRhat_SICI }\end{array}$ & $\begin{array}{l}-0.00017353 \\
-0.00019451\end{array}$ & $* * *$ & $\begin{array}{r}\text { DHRhat_Italy_CSUD } \\
\text { HRhat_CSUD }\end{array}$ & $\begin{array}{r}-0.00017265 \\
-1.50 \mathrm{E}-06\end{array}$ & $* * *$ \\
\hline HRhat_Italy_SICI & $9.50 \mathrm{E}-08$ & $* * *$ & HRhat_Italy_CSUD & $-1.59 \mathrm{E}-08$ & $* * *$ \\
\hline SSR & 36231939 & & SSR & 1509701 & \\
\hline S.E of regression & 28.80871 & & S.E of regression & 5.880626 & \\
\hline R-squared & 0.266414 & & R-squared & 0.060816 & \\
\hline Dependent & variable: & CCT_SARD & Dependent & variable: & CCT_CNOR \\
\hline & Coefficient & p-value & Coefficient & Std.Error & \\
\hline DHRhat_SARD & 0.00632313 & $* * *$ & DHRhat_CNOR & 0.00125167 & $* * *$ \\
\hline DHRhat_Italy_SARD & 0.00030026 & $* * *$ & DHRhat_Italy_CNOR & $-4.85 \mathrm{E}-05$ & *** \\
\hline HRhat_SARD & $-6.41 \mathrm{E}-06$ & & HRhat_CNOR & $-3.09 \mathrm{E}-06$ & $* * *$ \\
\hline HRhat_Italy_SARD & $2.32 \mathrm{E}-08$ & ** & HRhat_Italy_CNOR & $-2.21 \mathrm{E}-08$ & *** \\
\hline SSR & 25572825 & & SSR & 1039809 & \\
\hline S.E of regression & 24.2029 & & S.E of regression & 4.880393 & \\
\hline R-squared & 0.065527 & & R-squared & 0.062649 & \\
\hline
\end{tabular}

Table 11: Estimation result of explicit congestion cost (CCT)

Our findings indicate that rising renewable or hydro production in the given zone will push CCT towards negative value.This is due to merit order effects that shift the supply function in the zonal market thus producing lower congestion cost. Then, pushing renewable penetration much further could dissipate the congestion , $(C C T=$ 0 ), or continue to decrease the price, $(C C T<0)$, due to abundance efficient supply that saturate the lines. In the latter case, the given zone shift into an exporting zone $\left(P \_Z O N E<P U N\right)$ and all producers in this zone are penalized from contributing to the congestion. The same output can be captured in the lower demand at the given zone. On the contrary, increasing renewable from outside the zone (rest of Italy) will trigger maximization of the transmission line, which subsequently increases the PUN price on the market equilibrium. As for the load, lower value from outside of the zone (rest of Italy) will shift the equilibrium thus producing lower PUN price. Consequently, it provides advantages for power producers as they may benefit higher rewards $\left(P_{-} Z O N E>P U N\right)$ or lower congestion cost $\left.\left(P_{-} Z O N E<P U N\right)\right)$

In the case of ICC, we follow the intuition from Woo et al.(2011) analysis on the Texas electricity market where rising demand in non-west zones (fewer wind resource) and high wind output from west increases price difference. Hence, the results should provide a positive value on $D H R \_Z O N E 1$ while negative value $D H R \_Z O N E 2$. Our hypotheses are proven in our estimation displayed in table 12.

1) In importing zone (ZONE1):

- Coefficients of $D H R_{\_} Z O N E$ suggest that increasing demand or lower renewable or hydro increase the congestion cost;

- Importing zones of SICI-SUD, SARD-CSUD and CSUD-SUD have the highest impact as it can increase the congestion cost for $0.0351 €, 0.013 €$ and 0.0029 €per Mwh increase in demand (or decrease in renewable);

- $H R_{-} Z O N E$ imply that larger hydro coupled with larger renewable production could decrease the congestion cost much further towards negative value (Positive value is found in the case of CSUD-SUD and SARD-CSUD); 
- Improting zones of SICI-SUD and CNOR-NORD have the highest impact as it can further decrease the congestion cost for $0.0001 €$ and $0.0000069 €$ €per Mwh increase in renewable coupled with hydro;

2) In exporting zone (ZONE2):

- Coefficients of $D H R_{-} Z O N E$ show that increasing demand or lower renewable or hydro decrease the congestion cost (with the exception of SARD-CSUD);

- Exporting zones of SICI-SUD , CSUD-SUD and CNOR-CSUD have the highest impact as it can decrease the congestion cost for $0.005 €, 0.0022 €$ Gand 0.0015 €per Mwh increase in demand (or decrease in renewable);

- $H R_{-} Z O N E$ suggest that larger hydro coupled with larger renewable in the exporting zone of CSUD-SUD, SICI-SUD and CNOR-CSUD could increase the congestion cost much further towards positive value (opposite behavior can be found on SARD-CSUD and CNOR-NORD);

- Exporting zones of SICI-SUD and CNOR-CSUD have the highest impact as it can increase the congestion cost for 0.0000057 €and 0.0000026 €per Mwh increase in renewable coupled with hydro.

\begin{tabular}{|c|c|c|c|c|c|}
\hline Dependent & variable: & CNOR_NORD & Dependent & variable: & CSUD_SUD \\
\hline & Coefficient & p-value & & Coefficient & $\mathrm{p}$-value \\
\hline DHRhat_CNOR & 0.00260924 & & DHRhat_CSUD & 0.00297075 & \\
\hline DHRhat_NORD & -0.00040112 & $* * *$ & DHRhat_SUD & -0.00220462 & $* * *$ \\
\hline HRhat_CNOR & $-6.93 \mathrm{E}-06$ & $* * *$ & HRhat_CSUD & $6.60 \mathrm{E}-06$ & $* * *$ \\
\hline HRhat_NORD & $-2.63 \mathrm{E}-08$ & *** & HRhat_SUD & $1.08 \mathrm{E}-06$ & *** \\
\hline SSR & 1600184 & & SSR & 2668576 & \\
\hline S.E of regression & 6.054287 & & S.E of regression & 7.818399 & \\
\hline R-squared & 0.097813 & & R-squared & 0.125821 & \\
\hline Dependent & variable: & CNOR_CSUD & Dependent & variable: & SICI_SUD \\
\hline & Coefficient & p-value & & Coefficient & p-value \\
\hline DHRhat_CNOR & 0.00161601 & $* * *$ & DHRhat_SICI & 0.0351641 & $* * *$ \\
\hline DHRhat_CSUD & -0.0015499 & $* * *$ & DHRhat_SUD & -0.00562983 & $* * *$ \\
\hline HRhat_CNOR & $-3.73 \mathrm{E}-06$ & $* * *$ & HRhat_SICI & -0.00010442 & $* * *$ \\
\hline HRhat_CSUD & $2.60 \mathrm{E}-06$ & $* * *$ & HRhat_SUD & $5.70 \mathrm{E}-06$ & *** \\
\hline SSR & 1525946 & & SSR & 37992233 & \\
\hline S.E of regression & 5.91218 & & S.E of regression & 29.50023 & \\
\hline R-squared & 0.037288 & & R-squared & 0.312282 & \\
\hline Dependent & variable: & SARD_CSUD & & & \\
\hline & Coefficient & p-value & & & \\
\hline DHRhat_SARD & 0.0136536 & $* * *$ & & & \\
\hline DHRhat_CSUD & 0.00111795 & $* * *$ & & & \\
\hline HRhat_SARD & 0.00017197 & *** & & & \\
\hline HRhat_CSUD & $-4.75 \mathrm{E}-06$ & $* * *$ & & & \\
\hline SSR & 26731158 & & & & \\
\hline S.E of regression & 24.74497 & & & & \\
\hline R-squared & 0.061857 & & & & \\
\hline
\end{tabular}

Table 12: Estimation result of implicit congestion cost

In comparison to Woo et al. (2011) and the case of CCT, identical mechanism can be implied from our estimations. Lower demand or higher renewable supply in the importing zone may push lower zonal equilibrium prices, which impact the congestion cost towards negative value. As in CCT, higher growth of renewable production could change the net flow condition, which can be either a less-saturated line resulted in the merge of both zones $(I C C=0)$ or change the directions of electricity $(I C C<0)$. The same idea can be preserved in low growth (or simply smaller) demand in the importing zone. The changes or shock towards negative value will result in excessive efficient supply or less saturated congestion. Therefore, the congestion cost could be negative (in the case of excessive supply) and zero (in the case of less saturation). The 
opposite behavior can be applied in the exporting zone. Larger renewable or hydro will occupy the transmission capacity and create a new zone, an importing zone. As a consequence, low efficiency units are called in the importing zone for balancing the system and the congestion cost (ICC) increases.

\begin{tabular}{lcc}
\hline & DHR_ZONE* & HR_ZONE** \\
\hline CCT & $\begin{array}{r}\text { ZONE: } \uparrow \\
\text { Italy_ZONE: } \downarrow\end{array}$ & $\begin{array}{c}\text { ZONE: } \downarrow \\
\text { Italy_ZONE: } \uparrow\end{array}$ \\
\hline \multirow{2}{*}{ ICC } & ZONE1: $\uparrow$ & ZONE1: $\downarrow$ \\
ZONE2: $\downarrow$ & ZONE $2: \uparrow$ \\
\hline$*$ Increase of demand or lower renewable (hydro) supply \\
$* *$ Increase of renewable coupled with hydro supply
\end{tabular}

Table 13: 3 SLS result summary

We may sum and generalize our finding as the table 13. Due to the merit order effect, rising renewable (hydro or lower demand) decrease the price equilibrium and subsequently push the congestion cost towards negative value. Additional impact on the congestion cost may occur if larger renewable is coupled with larger hydro. This conclusion is applied for supplies from the importing zones (ZONE1), in the case of ICC, and both importing and exporting zones (ZONE), in the case of CCT. However, it is important to be noted that, continuous reduction of congestion cost will subsequently merge the zone (congestion cost $=0$ ) since the transmission line is less saturated from the import. Hence, bigger shock may change the direction of the flow (congestion cost $<0$ ) since there is excessive efficient supply needs to be transferred. On their respective counter flow zones (ZONE2 and Rest of Italy), an opposite behavior is observed as the merit order effect shift price equilibrium of ZONE2 and PUN. Moreover, additional impact is captured if big renewable is coupled with large hydro. Therefore, from the point of view of Terna, increase of renewable should be promoted in the importing zones as they tend to reduce the congestion cost in both CCT and ICC or create less saturated line $(C C T=I C C=0)$. Then, excessive growth in all the zones should be avoided in order to avoid excessive efficient supply that cause congestion.

\section{Conclusion}

Our empirical analysis has shown that demand and renewable supply have different impacts on the congestion occurrence and cost. The results of the multinomial logit model suggests that the effect of a larger local renewable supply is to decrease the probability of suffering congestion in entry and to increase the probability of causing a congestion in exit compared to no congestion case. Increasing hydroelectric production has a similar effect. A rise in local demand on the contrary increases the probability of congestion in entry (due to larger import) and decreases the probability of congestion in exit. This results holds for both importing and exporting regions. However, the importing regions are less likely to produce congestion in exit. Therefore a larger RES production in these regions is expected to bring more balances in flows between neighboring regions, while a larger RES production in exporting zones may exacerbate the problem of congestion. On the other hand, estimation on congestion cost suggest that lower demand and larger renewable shift the congestion cost towards negative. Then, additional decrease in congestion cost will be found if larger renewable is coupled with larger hydro. Therefore, continuous increase of renewable (negative shock in demand) may consolidate two neighboring zones into one or may change the direction of the electricity. This is particularly true in all the case of 
CCT and all importing zones on ICC. In their respective opposite direction of the counterflow (Rest of Italy and exporting zone), exact opposite impacts are displayed.

Both of our estimations allow us to draw some conclusion for policy construction.

- Additional incentive in the importing regions.

Increase of renewable in the importing zones provides a more balanced system since it less likely to produce congestion in exit and reduces the odds for congestion in entry. In addition, both CCT and ICC could be reduced or dissipated as they shift the zonal price equilibrium towards negative value. Therefore, in the point of view of TSO and policy maker, further promotion of renewable growth in importing regions is recommended. In the current state, operators would prefer rising renewable in the exporting zones since they could profit from the high zonal price and congestion cost.

- Growth of intermittent supply should be controlled.

Although it is true that larger renewable decrease the congestion cost and reduce the frequency, bigger shock may provide an opposite effect. Rising renewable increase the odds for congestion in exit regardless of the zones and the estimation in congestion cost validate this phenomenon as continuous increase may change the net flow direction (congestion cost $<0$ ). Hence, excessive growth will worsen the congestion problems.

- Identical behavior will occur in the large scale.

If a larger scale market (e.g Europe) is done under the same algorithm and bidding zone system, similar behavior should be seen. For instance, high demand in importing countries (zones) will stimulate exports of efficient supply from the neighboring countries (zones), thus increasing the odds for congestion in entry and increase its cost. However, the market would require well-organised transmission management and detailed research on bidding zones since several TSO are involved.

There are several directions that can be pursued in order to capture the full picture of the electricity market. It is important to be noticed that there are few econometric studies in this line of research, thus future extensive studies may be needed to obtain better views on RES and congestion. Our paper assumes non-inference bids, which allow us to simplify the problem. Therefore, more research can be directed towards strategical bidding in the electricity market. With more renewable supply in the market, it is important to understand renewable impact on the thermal units' bids.

\section{Acknowledgments}

Silvia Concettini gratefully acknowledges the financial support from the ANR - Investissements d'avenir (ANR-11-IDEX-0003-02) and from the chair Energy and Prosperity at Fondation du Risque (ILB). 


\section{References}

[1] Clo, S., Cataldi, A. and Zoppoli, P., 2015, "The merit-order effect in the Italian power market: The impact of solar and wind generation on national wholesale electricity prices", Energy Policy, 77, 79-88.

[2] Concettini, S., 2014, "Merit order effect and strategic investments in intermittent generation technologies", EconomiX Working Paper No. 2014-44.

[3] Cutler, N.J., Boerema, N.D., MacGill, I.F., Outhred, H.G., 2011, "High penetration wind generation impacts on spot prices in the Australian national electricity market", Energy Policy, 39, 5939-5949.

[4] Gelabert, L., Labandeira, X., and Linares, P., 2011, "An ex-post analysis of the effect of renewables and cogeneration on Spanish electricity prices", Energy Economics, 33 (S1), 59-65.

[5] Gianfreda, A. and Grossi, L., 2012, "Forecasting Italian Electricity Zonal Prices with Exogenous Variables", Energy Economics, 34 (6), 2228-2239.

[6] Hemdan, G.A.N., Kurrat, M., Schmedes, T., Voigt, A., and Busch, R., 2014, "Integration of superconducting cables in distribution networks with high penetration of renewable energy resources: Techno-economic analysis", International Journal of Electrical Power $\&$ Energy Systems, Volume 62.

[7] Jónsson, T., Pinson, P., and Madsen, H, 2010, "On the market impact of wind energy forecasts", Energy Economics, 32 (2), 313-320.

[8] Ketterer, J.C., 2014, "The impact of wind power generation on the electricity price in Germany", Energy Economics, 44, 270-280.

[9] Milstein, I. and Tishler, A., 2011, "Intermittently renewable energy, optimal capacity mix and prices in a deregulated electricity market", Energy Policy, 39 (7), 3922-3927.

[10] O'Mahoney, A. and Denny, E., 2011, “The merit-order effect of wind generation in the Irish electricity market", Proceedings of the 30th USAEE/IAEEE North American Conference, USAEE, Washingotn D.C., USA.

[11] Sapio, A., 2014, "Renewable flows and congestion in the Italian power grid: Binary time series and vector autoregressions", Proceedings for the 47th Scientific Meeting of the Italian Statistical Society.

[12] Schröeder, A., Oei, P.Y., Sander, A., Hankel, L., and Laurisch, L.C., 2013, "The Integration of Renewable Energies into the German Transmission Grid: A Scenario Comparison", Energy Policy, 61, 140-150.

[13] Woo, C.K., Zarnikau, J., Moore, J., and Horowitz, I., 2011, "Wind generation and zonal-market price divergence: Evidence from Texas", Energy Policy, 39(7), 3928-3938.

[14] Wurzburg, K., Labandeira, X., and Linares, P., 2013, "Renewable generation and electricity prices: Taking stock and new evidence for Germany and Austria", Energy Economics, 40 (1), Supplement Issue: Fifth Atlantic Workshop in Energy and Environmental Economics, 159-171. 
Appendix A Additional figures

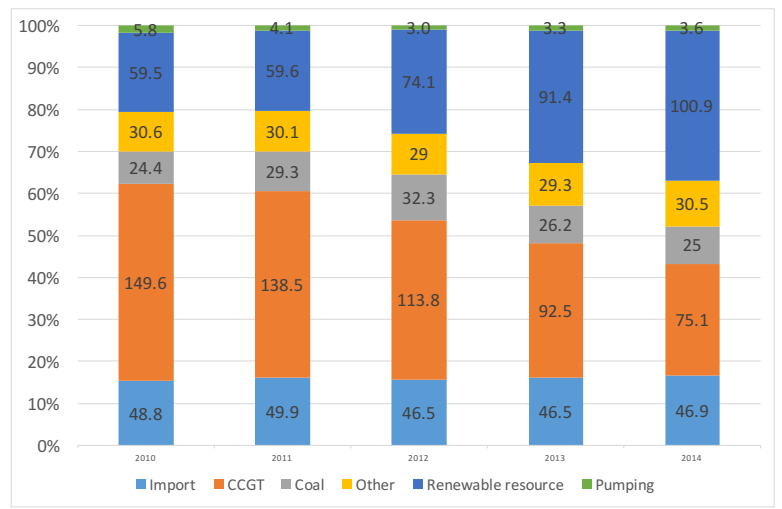

Figure 9: Accepted quantity in the day-ahed market by source (Twh), 2010-2014 


\section{Appendix B Multinomial logit: Descriptive statis- tics and Tables}

\begin{tabular}{lrr}
\hline \multicolumn{1}{c}{ Variable } & Mean & Std. Dev. \\
\hline CNOR_Hydro & 257.513 & 173.97 \\
CNOR_Wind & 7.934 & 10.38 \\
CNOR_NRRes & 353.457 & 320.536 \\
CNOR_PV & 1.203 & 2.733 \\
CNOR_PV_Tot & 354.66 & 322.328 \\
CNOR_D & 3524.293 & 879.753 \\
\hline
\end{tabular}

\begin{tabular}{lrr}
\hline \multicolumn{1}{c}{ Variable } & Mean & Std. Dev. \\
\hline SARD_Hydro & 34.064 & 35.458 \\
SARD_Wind & 126.031 & 142.605 \\
SARD_NRRes & 54.567 & 76.789 \\
SARD_PV & 3.793 & 8.753 \\
SARD_PV_Tot & 58.36 & 84.416 \\
SARD_D & 1376.044 & 251.241 \\
\hline & & \\
\hline Variable & Mean & Std. Dev. \\
\hline SICI_Hydro & 11.008 & 12.143 \\
SICI_Wind & 260.465 & 218.838 \\
SICI_NRRes & 140.622 & 193.418 \\
SICI_PV & 1.94 & 4.398 \\
SICI_PV_Tot & 142.562 & 196.973 \\
SICI_D & 2203.172 & 410.19 \\
\hline & & \\
\hline Variable & Mean & Std. Dev. \\
\hline SUD_Hydro & 192.663 & 168.872 \\
SUD_Wind & 527.586 & 421.578 \\
SUD_NRRes & 443.762 & 564.546 \\
SUD_PV & 13.558 & 25.532 \\
SUD_PV_Tot & 457.32 & 587.877 \\
SUD_D & 2917.71 & 554.735 \\
\hline
\end{tabular}

\begin{tabular}{ll}
\hline Variable & Description \\
\hline Hydro & Hydroelectric production \\
Wind & Wind production \\
NRRes & RES production from Non Relevant Unit (Power $<10 \mathrm{MVA})$ \\
PV & Photovoltaic production \\
PV_Tot & Large and small photovoltaic production \\
D & Demand \\
\hline
\end{tabular}

Table 14: List of regressors and descriptive statistics, 2010-2014 


\begin{tabular}{lrr}
\hline Status in CNOR-NORD & Number & Per cent \\
\hline Congestion from CNOR & 1,992 & 5 \\
No congestion & 40,122 & 92 \\
Congestion to CNOR & 1,710 & 4 \\
Total & 43,824 & 100 \\
\hline Status in CNOR-CSUD & Obs & Per cent \\
\hline Congestion from CNOR & 620 & 1 \\
No congestion & 40,026 & 91 \\
Congestion to CNOR & 3,178 & 7 \\
Total & 43,824 & 100 \\
\hline Status in SARD-CSUD & Obs & Per cent \\
\hline Congestion from SARD & 469 & 1 \\
No congestion & 36,556 & 83 \\
Congestion to SARD & 6,799 & 16 \\
Total & 43,824 & 100 \\
\hline Status in CSUD-SUD & Obs & Per cent \\
\hline No congestion & 37,183 & 85 \\
Congestion to CSUD & 6,641 & 15 \\
Total & 43,824 & 100 \\
\hline Status in SICI-SUD & Obs & Per cent \\
\hline Congestion from SICI & 2,963 & 7 \\
No congestion & 8,060 & 18 \\
Congestion to SICI & 32,801 & 75 \\
Total & 43,824 & 100 \\
\hline
\end{tabular}

Table 15: Network status in neigbouring regions, 2010-2014 Congestion from $=$ first region has lower price

No congestion $=$ Equal prices
Congestion to= first region has higher price 


\section{Appendix C 3 Stage Least Squares: Descriptive statis- tics and Tables}

\begin{tabular}{lrr}
\hline Variable & Mean & Std. Dev \\
\hline R_CNOR & 362.59 & 324.13 \\
R_CSUD & 571.98 & 447.92 \\
R_NORD & 2239.8 & 1168.9 \\
R_SARD & 184.39 & 172.71 \\
R_SICI & 403.03 & 308.82 \\
R_SUD & 984.91 & 768.21 \\
H_CNOR & 273.83 & 182.25 \\
H_CSUD & 364.44 & 217.17 \\
H_NORD & 3490.3 & 1721.8 \\
H_SARD & 47.943 & 55.496 \\
H_SICI & 12.633 & 15.372 \\
H_SUD & 192.66 & 168.87 \\
D_CNOR & 3524.3 & 879.75 \\
D_CSUD & 5311 & 1189.1 \\
D_NORD & 18467 & 4238.2 \\
D_SARD & 1376 & 251.24 \\
D_SICI & 2203.2 & 410.19 \\
D_SUD & 2917.7 & 554.73 \\
\hline
\end{tabular}

\begin{tabular}{|c|c|}
\hline Variables & Description \\
\hline H_ZONE & Aggregate hydro output in the given zone (including run-of-river and pompage) \\
\hline R_ZONE & $\begin{array}{l}\text { Summation of accepted bidding quantity in the given zone from: } \\
\text { - Wind turbine units } \\
\text { - Photovoltaic units } \\
\text { - Non-relevant renewable units } \\
\text { - Bids from GSE }\end{array}$ \\
\hline D_ZONE & Total purchased electricity in the given zone \\
\hline
\end{tabular}

Table 16: List of regressors and descriptive statistics, 2010-2014

\begin{tabular}{lrrrrr}
\hline & Mean & Std. & Jarque-Bera & ADF1 & ADF2 \\
\hline CCT_CNOR & -1.7534 & 5.037 & 0 & $<1 \%$ & $<1 \%$ \\
CCT_CSUD & -2.4306 & 6.0674 & 0 & $<1 \%$ & $<1 \%$ \\
CCT_NORD & -1.7502 & 4.6511 & 0 & $<1 \%$ & $<1 \%$ \\
CCT_SARD & 4.3833 & 25.004 & 0 & $<1 \%$ & $<1 \%$ \\
CCT_SICI & 24.821 & 33.61 & 0 & $<1 \%$ & $<1 \%$ \\
CCT_SUD & -4.7852 & 9.0225 & 0 & $<1 \%$ & $<1 \%$ \\
CNOR_NORD & -0.0031427 & 6.3730 & 0 & $<5 \%$ & $<1 \%$ \\
CNOR_CSUD & 0.67725 & 6.0271 & 0 & $<1 \%$ & $<1 \%$ \\
SARD_CSUD & 6.8139 & 25.519 & 0 & $<1 \%$ & $<1 \%$ \\
CSUD_SUD & 2.3545 & 8.4058 & 0 & $<1 \%$ & $<1 \%$ \\
SICI_SUD & 29.606 & 35.586 & 0 & $<1 \%$ & $<1 \%$ \\
\hline
\end{tabular}

Table 17: Summary statistics of the dependent variables, 2010-2014 


\section{Appendix D Stationarity}

Table 18: Statistic summary of the regressors

\begin{tabular}{lrrr}
\hline & Jarque-Berra & ADF1 & ADF2 \\
\hline R_CNOR & 0 & 1 & $<1 \%$ \\
R_CSUD & 0 & 1 & $<1 \%$ \\
R_NORD & 0 & 1 & $<1 \%$ \\
R_SARD & 0 & $<1 \%$ & $<1 \%$ \\
R_SICI & 0 & $<1 \%$ & $<1 \%$ \\
R_SUD & 0 & $<1 \%$ & $<1 \%$ \\
H_CNOR & 0 & $<1 \%$ & $<1 \%$ \\
H_CSUD & 0 & $<1 \%$ & $<1 \%$ \\
H_NORD & 0 & $<1 \%$ & $<1 \%$ \\
H_SARD & 0 & 1 & $<1 \%$ \\
H_SICI & 0 & $<5 \%$ & $<1 \%$ \\
H_SUD & 0 & 1 & $<1 \%$ \\
D_CNOR & 0 & $<1 \%$ & $<1 \%$ \\
D_CSUD & 0 & $<1 \%$ & $<1 \%$ \\
D_NORD & 0 & $<1 \%$ & $<1 \%$ \\
D_SARD & 0 & $<1 \%$ & $<1 \%$ \\
D_SICI & 0 & $<1 \%$ & $<1 \%$ \\
D_SUD & 0 & $<1 \%$ & $<1 \%$ \\
\hline
\end{tabular}

Stationary test is required in order to avoid spurious regression. In addition, the test is also necessary to identify the deterministic trend in our data and builds our regression equation. We use augmented Dickey fuller (ADF) test in this study. The result of our test can be seen in the table 17 and 18. The initial test uses the equation below for the first identification.

$$
z_{t}=\Gamma+\tau T+\lambda z_{t-1}
$$

Where, $z_{t}$ is the value of variable $z$ at time $\mathrm{t}, z_{t-1}$ is the value of variable $z$ at time $t-1, \Gamma$ is a constant, $T$ is the time trend. The null hypothesis is that $\lambda=1$, and the data can be concluded as non-stationary under constant and trend.

The results show that most of our data was already statistically stationary in constant and trend. Demand from all the zones and all dependent variables are stationary under this setting. Unfortunately, hydro productions and renewable supply are still not stationary. Therefore, seasonality trends are needed to be added in the regression. Another test is applied with a regression as follows.

$$
z_{t}=\Gamma+\tau T++\sum_{i=1}^{i=23} \delta_{i} D_{i}+\lambda z_{t-1}
$$

It can be observed that we add hourly dummies for capturing the seasonality trend since we have the data under this frequency. We also omitted dummies for the hour 24 in order to avoid multicollinearity in regression. The results show that our data are stationary under constant, time and seasonal trend for both dependent variables and regressors. Hence, these three important features need to be integrated in our regression equations in order to de-trend the data. 